Portland State University

PDXScholar

$12-13-1996$

\title{
Distribution of R-Banded Chromosome Variants in a Bottlenose Dolphin (Tursiops Truncatus) Population
}

Kristine Anne Gunter

Portland State University

Follow this and additional works at: https://pdxscholar.library.pdx.edu/open_access_etds

Part of the Molecular Biology Commons

Let us know how access to this document benefits you.

Recommended Citation

Gunter, Kristine Anne, "Distribution of R-Banded Chromosome Variants in a Bottlenose Dolphin (Tursiops Truncatus) Population" (1996). Dissertations and Theses. Paper 5406.

https://doi.org/10.15760/etd.7279

This Thesis is brought to you for free and open access. It has been accepted for inclusion in Dissertations and Theses by an authorized administrator of PDXScholar. Please contact us if we can make this document more accessible: pdxscholar@pdx.edu. 
The abstract and thesis of Kristine Anne Gunter for the Master of Science in Biology were presented December 13, 1996, and accepted by the thesis committee and the department.

COMMITTEE APPROVALS :

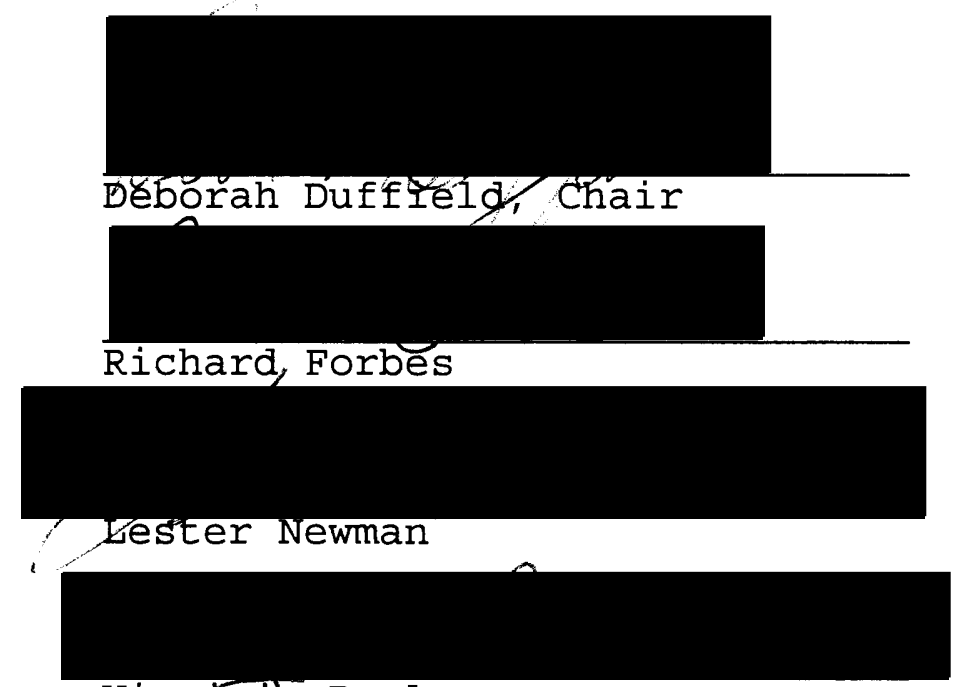

Virginia Butler

Representative of the Office of Graduate studies

DEPARTMENT APPROVAL:

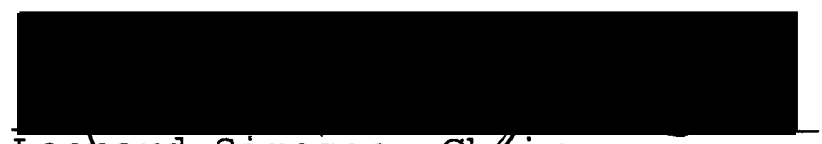

Leohard Simpson, Chair

Department of Biology

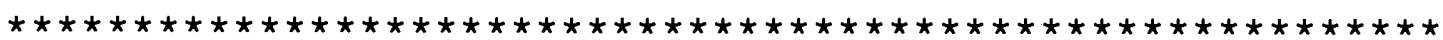

ACCEPTED FOR PORTLAND STATE UNIVERSITY BY THE LIBRARY

by

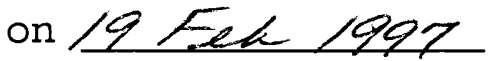


An abstract of the thesis of Kristine Anne Gunter for the Master of Science in Biology presented December 13, 1996.

Title: Distribution of $\mathrm{R}$-Banded Chromosome Variants in $\mathrm{A}$ Bottlenose Dolphin (Tursiops truncatus)

Population

When combined with observational and behavioral data, chromosome variant analysis provides a means of assessing population structure in bottlenose dolphins, Tursiops truncatus. In this cytogenetic analysis of thirty-six bottlenose dolphins, a distribution of fluorescent R-band variants was catalogued and used as a way to characterize the genetic structure of a Tursiops population inhabiting the Matagorda Bay, Texas, area.

Three different population genetic analytical techniques were evaluated for their usefulness in analyzing cytogenetic data. The chromosome variant data obtained from this study was then compared with cytogenetic data gathered from a resident dolphin population residing near Sarasota, Florida.

The purpose of this study was to measure the genetic differences that existed within the Matagorda Bay study population, as well as measure the differences which exist when comparing the Matagorda Bay animals to the Sarasota Bay population. The comparison of these two geographically separated populations gave a quantitative 
baseline from which to evaluate the significance of the level of local differentiation and subgroup structure. Each population genetic analytical method demonstrated that subgroup differentiation existed within the Matagorda Bay sample. The cytogenetic data, therefore, suggest that the Tursiops in Matagorda Bay most likely do not represent a single breeding unit or population. The Matagorda Bay area could instead be viewed as a region which is inclusive of the home ranges of multiple subgroups of Tursiops. These subgroups of animals presumably interact with one another, and the migration of animals into and out of subgroups serves as a method of genetic exchange among the animals in this region. The extent of migration of animals throughout the Gulf of Mexico is not known, but several chromosome variants previously identified in the sarasota animals were not present in the Matagorda Bay sample and vice versa.

The cytogenetic data obtained through this study suggests that coastal, in-shore Tursiops populations in the Gulf of Mexico may be best characterized as a series of local, but inter-mixing populations. Chromosomal variants are transmitted from core area to core area via individual animals that do not maintain core area fidelity. 
DISTRIBUTION OF R-BANDED CHROMOSOME VARIANTS IN A BOTTLENOSE DOLPHIN (TURSIOPS TRUNCATUS) POPULATION

by

KRISTINE ANNE GUNTER

A thesis submitted in partial fulfillment of the requirements for the degree of

MASTER OF SCIENCE

in

BIOLOGY

Portland State University

1997 
First and foremost, I must extend my deepest gratitude to Debbie Duffield for having the courage to accept me as her graduate student. After having been told that I would, in all likelihood, not have much success as a graduate student in biology, she believed in me, encouraged me and taught me. To her, I dedicate my thesis. To those who didn't believe in my success, I dedicate my 4.00 graduate GPA.

This thesis wouldn't be complete without mentioning other people who have provided assistance, mentoring and guidance. Lester Newman introduced me to cytogenetics and to this day serves as my personal career counselor. Thanks Lester.

The clinical and research cytogenetics laboratories at the Oregon Health Sciences University have served as my home-away-from-home for the last five years. Working with some of the finest research scientists and clinical cytogenetic technicians in the country has both inspired me and taught me to appreciate a job well done.

And of course, I can't forget to mention my family, who after six and one-half years of asking me, "When are you going to finish graduate school?" will have to think of another question to start asking me. Thanks to my mom, my dad, my sisters and everyone else in my family 
for their encouragement. And thanks to Claude who spent many evenings at the computer "helping" me.

And finally, a "thank-you" to my husband Eric, who has provided me with emotional support and love during this graduate degree quest of mine. What a journey it has been! 
ACKNOWLEDGMENTS ....................

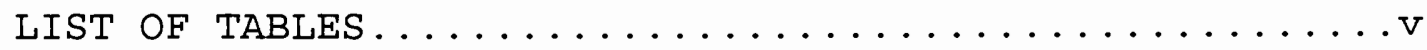

LIST OF FIGURES......................

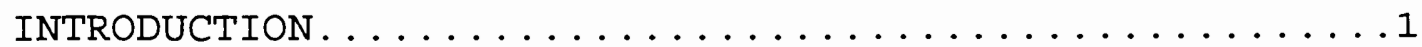

Taxonomic status of Tursiops truncatus..........

Communities and Associations

Formed Within Dolphin Populations......2

Genetic Studies of Cetacean Populations........4

Cytogenetic Analysis of Populations...........

Cytogenetic Analysis of Cetaceans............

Thesis Project: Matagorda Bay Tursiops Study.....11

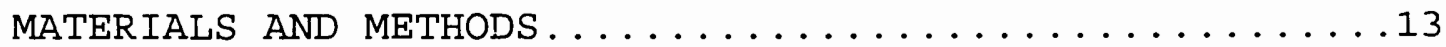

Matagorda Bay Tursiops Population...........13

Chromosome Cultures...................14

Chromosome Variant Analysis.............16

Statistical Analysis..................16

Population Equilibrium Estimates

Pair-Wise Similarity Coefficients

Nei Index for Measuring Allelic Frequency

Differences

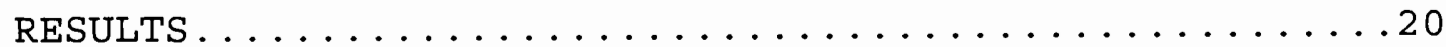

Heteromorphism Analysis................20

Statistical Analysis...................22

Population Equilibrium Estimates

Pair-Wise Similarity Coefficients

Nei Index for Measuring Allelic Frequency

Differences 
Evaluation of Maternity and Paternity.........29

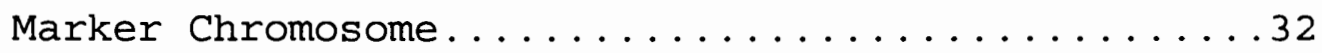

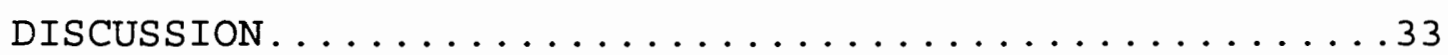

Behavioral Observations of Sample Population.....33

R-Banded Chromosome Variation as a

Method for Comparing Populations...........35

Hardy-Weinberg Equilibrium Estimates

Population Pooling

Pair-Wise Similarity Coefficients

Nei Index for Measuring Allelic Frequency

Differences

Unique Variants

Evaluation of Mother/Calf and

Father/Calf Pairs

Analysis of Techniques To

Assess Genetic Differences............48

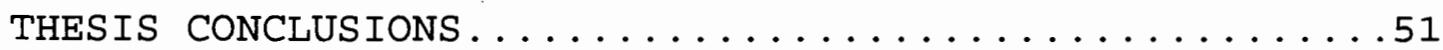

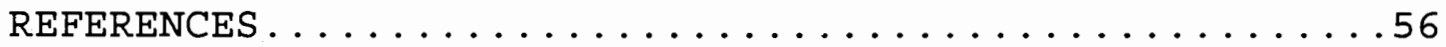

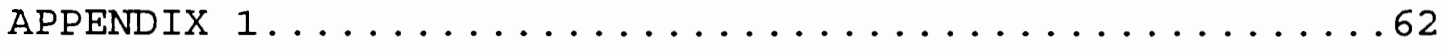

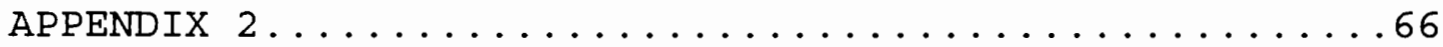

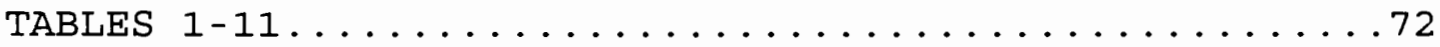

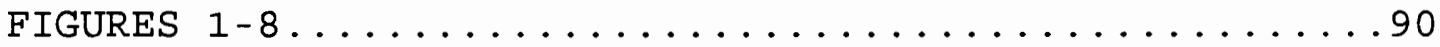


TABLE 1: Summary information of Matagorda Bay

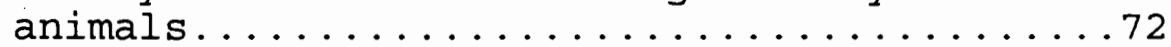

TABLE 2: Summary of chromosomal variants for each of the 35 animals studied..............74

TABLE 3: Distribution of variant genotypes among Matagorda Bay sample population......75

TABLE 4: Frequencies of individual chromosomal variants for Matagorda Bay population......76

TABLE 5: Results of Hardy-Weinberg tests--comparison of Sarasota population with Matagorda Bay...77

TABLE 6: Comparison of variant and phenotypic frequencies for male and female populations sampled from Matagorda Bay for chromosome variable region $18 \mathrm{p} \ldots \ldots \ldots . \ldots 79$

TABLE 7: Results of Hardy-Weinberg tests--male and female comparison within Matagorda Bay.....80

TABLE 8: Results of Hardy-Weinberg tests--Intrapopulation comparison within Matagorda Bay..82

TABLE 9: Similarity values for 595 pair-wise comparisons made among the Matagorda Bay

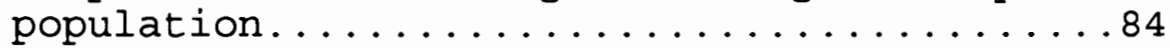

TABLE 10: Comparisons of similarity index values for three different pairs of population subgroups..................... 88

TABLE 11: Similarity values and $Z$-scores for the five potential mother and calf pairs from the Matagorda Bay sample..............89 
FIGURE 1: Map of the Port 0 'Connor area of Matagorda Bay........................90

FIGURE 2: Chromosome variants identified among the Matagorda Bay animals...............91

FIGURE 3: Distribution of pairwise similarity values for the Matagorda Bay sample...........93

FIGURE 4: Distribution of pairwise similarity values for NE group and SW group of animals from within Matagorda Bay sample...........94

FIGURE 5: Ages and sex of suspected mother-calf pairs..95

FIGURE 6: Discrepant chromosome pairs in suspected mother-calf pairs................96

FIGURE 7: Similarity values for suspected mother-calf pairs in Matagorda Bay, in comparison to the similarity values calculated for the entire sample..................97

FIGURE 8: Distribution of unique variants between Matagorda Bay and Sarasota............98 


\section{Introduction}

Taxonomic status of Tursiops truncatus

Bottlenose dolphins (Tursiops truncatus) reside worldwide in all tropical to temperate ocean locations (Darling et al.,1995), inhabiting in-shore areas as well as open ocean environments. Several issues regarding the taxonomic classification of in-shore and pelagic forms or regional distributions of Tursiops have not yet been resolved. For example, while differences in morphology, hematology and feeding habits have been found to distinguish coastal from off-shore populations (Duffield et al.,1983; Hersh and Duffield,1990; Scott and Chivers, 1990), whether these differences warrant recognition as separate species has not been established.

Ross and Cockcraft (1990) reviewed the issue of speciation within the genus Tursiops, noting that some authors have suggested defining as many as four different species: T. truncatus, T. gilli, T. aduncus and T. gephyreus. Van waerebeek et al.,(1990), in a preliminary review of bottlenose dolphins residing along the Pacific coastline of South America, noted that while physical characteristics may distinguish off-shore from in-shore forms, the assumption should be that bottlenose dolphins consist of a single species, T. truncatus, distinguishable by a series of unique geographical forms. 
Communities and Associations Formed Within Dolphin Populations

Site fidelity is thought to be a common feature of coastal populations of bottlenose dolphins (Irvine et al.,1981; Scott et al.,1990; Shane et al.,1986; Wells et al.,1980; Wells et al.,1987; Wells,1991; Würsig and Harris, 1990). Studies in western Australia, central western Florida and Argentina have shown that Tursiops populations inhabit specific regions of coastline for extended periods of time. Würsig and Harris (1990) were able to resight ten bottlenose dolphins in the same region off the Argentina coastline some eight to twelve years after an initial study had been completed. In addition, affiliations between certain animals within the population appeared to be maintained over the course of the twelve year period. Studies in Sarasota, Florida, have shown affiliations lasting over three generations (Wells, 1991).

Extensive long-term observational studies on bottlenose dolphin populations have provided insight into the behavior and individual associations formed in local Tursiops communities (Scott et al.,1990; Shane et al.,1986; Wells,1991). Observational studies have historically focused on coastal (in-shore) populations of Tursiops due to the ease with which these groups of 
animals can be studied. Off-shore populations inhabiting pelagic oceanic zones, as well as populations residing around islands have been studied less frequently (Scott and Chivers, 1990).

Long-term observational studies conducted on wild Tursiops populations residing near Sarasota, Florida, have provided insights into the group behavior of bottlenose dolphin communities (Scott et al.,1990; Irvine et al.,1981; Wells et al.,1980; Wells et al.,1987;

Wells,1991; Würsig and Harris,1990). Four major observations about Tursiops population dynamics have been noted from on-going studies in the Sarasota area:

1) Most Tursiops individuals utilize specific 'core areas' within a larger home range.

2) Bands of adult females will form within a Tursiops population. Members of a given band share a common home range and display relatively high degrees of association with one another.

3) Adult males travel widely throughout the Sarasota Bay area. Most males do not associate exclusively with any particular female band. Instead, they have ranges which encompass the core areas of multiple female bands.

4) Males and females show substantial differences in home ranges; females occupy relatively limited home ranges while males will range over greater distances. 
Adult males will travel from one female band to the next. Such differences in male and female distribution and movement patterns create the potential for sampling from two separate subgroups within a single region. Males and females which reside in adjacent areas may be identified, through behavioral observations, as members of the same population when in fact, they are representatives of neighboring subgroups, but interacting socially with one another.

\section{Genetic Studies of Cetacean Populations}

Genetic analyses of cetacean populations have helped to clarify issues regarding speciation, to investigate the management of populations and to define how different cetacean groups utilize core areas (Baker et al.,1993; Bigg,1982; Bigg et al.,1990; Danielsdòttir et al.,1991; Duffield,1982; Duffield,1986; Duffield and Wells,1986; Hoelzel and Dover, 1991). By comparing genetic data both within and between populations, hypotheses can be generated regarding breeding behavior. Groups of animals can be studied to determine if they represent isolated breeding groups or subpopulations within a large, intermingling population.

Populations of humpback whales (Megaptera novaeanglieae) were thought to be subdivided, based on 
observational data, into discrete subpopulations (Baker et al.,1993). DNA fingerprint and mitochondrial DNA (mtDNA) studies performed on North Pacific humpback populations provided additional evidence to substantiate demographic and behavioral information which suggested that this population was subdivided into relatively discrete subgroups which were not obviously geographically separated (Baker et al.,1993).

Behavioral studies of killer whales (Orcinus orca) have shown the existence of numerous discrete pods that do not appear to intermingle, yet live within the same geographical location (Bigg,1982; Bigg et al.,1990). Genetic studies of Pacific Northwest killer whale populations, performed using genomic DNA fingerprinting and/or mtDNA analysis, revealed that the genetic differences existing within the Vancouver Island sympatric population are as great as the genetic differences which are observed when comparing geographically isolated populations (Hoelzel and Dover,1991; Stevens et al.,1989). Other differences, including color morphology, acoustic behavior and feeding strategies distinguish the sympatric Vancouver Island killer whale populations from each other. These differences, when considered along with the genetic data suggesting that sympatric populations of the same species 
can be genetically isolated, led Hoelzel and Dover (1991) to suggest that the Vancouver Island killer whale population be managed as though it consists of separate stocks of animals.

Winans and Jones (1988) studied the electrophoretic variability present in a sample of 360 Dall's porpoises (Phocoenoides dalli) in order to help determine if the animals, taken from the North Pacific Ocean and from the Bering Sea, were representative of a single interbreeding population. Testing of the hypothesis involved comparing the protein electrophoretic variant frequencies among three selected subgroups within the population to those predicted by the Hardy-Weinberg equilibrium model. The subgroups were then pooled together and the variant frequencies for the population as a whole were calculated and compared to Hardy-Weinberg predictions. The authors reasoned that if the three subgroups sampled were indeed representative of a single breeding population, pooling of the data would not alter the Hardy-Weinberg results. When the analysis was performed, the Chi-square values in the "pooled" population exceeded those calculated for the individual subgroups at seven of nine variable loci tested, leading to the rejection of the null hypothesis that the samples were from a single interbreeding population. 


\section{Cytogenetic Analysis of Populations}

Cytogenetic variant analysis has helped to clarify and resolve speciation issues in a number of mammalian species. Matayoshi et al.,(1987), reported a characteristic heteromorphic chromosomal variant that appeared to be fixed within one subspecies population of Cebus apella (capuchin monkey). Taxonomic classification within this species has not been resolved with the number of subspecies and varieties reported as five, eleven and sixteen (Matayoshi et al.,1987). For one subspecies, C.a. xanthosternos, a characteristically different chromosome number eleven was identified with C-banding. All specimens of the subspecies were found to carry this distinguishable chromosome in a homozygous condition, suggesting that this is a fixed, not variable, chromosomal type. This finding, in conjunction with geographic distribution information and phenotypic identification helped to substantiate the existence of C.a. xanthosternos as a unique subspecies within the Cebus genus.

Cytogenetic variant analysis has been used in humans (Homo sapiens) as a method for paternity-testing, determination of uniparental disomy (UPD) and for assessing parental origin of extra chromosomes in trisomy 
13 and trisomy 21 cases (Magenis and Toth-Fejel,1992; Olson et al.,1983; Magenis et al.,1977). In 1975, an extensive study of a human newborn population was undertaken in order to determine the extent of polymorphic chromosome variation in humans. Of 376 newborns karyotyped using $\mathrm{C}$ - and $\mathrm{Q}$-banding techniques, polymorphism rates were so extensive that no two infants in the study had identical variant patterns (Müller et al.,1975). Subsequent studies performed by olson et al., (1986), found that within a human population the estimated probability of finding two persons with identical Q-band variants was 0.0003 .

\section{Cytogenetic Analysis of Cetaceans}

Overall, cetaceans show a highly conserved chromosome complement with respect to chromosome number and general structure. Early investigations of cetacean chromosomes revealed that most species have a $2 n=44$ chromosome count, with chromosomes in the majority of species having the same size and shape (Arnason,1974; Arnason et al.,1977; Arnason, 1981; Duffield,1977; Duffield-Kulu,1972). Stability of chromosome number and morphology within the cetaceans are attributed to three factors (Arnason, 1972): 
1) Cetaceans have a low reproductive rate, sexually maturing at a late age and producing only a single offspring each year.

2) Cetaceans show high degrees of mobility, often migrating thousands of miles each year.

3) Living in oceanic environments provides cetaceans with little opportunity to develop well defined niches.

All three factors promote a conservation of karyotype since a new rearrangement would have little chance of stabilizing in a mobile, inter-mixing population. Chromosome rearrangements are more likely to become fixed in small, isolated groups of individuals where inter-breeding is less likely to occur. Similarly, rare heteromorphic variants can be expected to become fixed only in small, closely related groups of individuals.

Despite the overall conservation of karyotype among the cetaceans, considerable variation in heterochromatic regions of chromosomes exists within this order (Arnason et al.,1980; Duffield,1977; Duffield,1986; Duffield et al.,1991; Duffield and Chamberlin-Lea,1990; Stock,1981). Cetacean chromosomes, therefore, may not provide an immediate means for identifying subspecies, but they can be used effectively as a method for comparing the variants between and among populations. These analyses 
can show a flow of variants from one population to another or show that variants are specific to one population only.

Chromosome heteromorphism analysis has been used as a method to look at population substructures (Duffield,1986; Duffield and Chamberlin-Lea,1990; Duffield and Wells,1991; Lambertson and Duffield,1987), identify unique subspecies populations (Matayoshi et al.,1987), determine paternity (Duffield and ChamberlinLea, 1990; Olson et al.,1986) and as a method for assessing the evolution of karyotypes among related species (Arnason et al.,1977; Arnason et al.,1980; Davis et al.,1986; Duffield,1977; Duffield et al.,1991; Stock, 1981). Chromosome variants can be visualized through the use of different staining techniques, including fluorescent R-banding (reverse banding), Qbanding (quinacrine banding) and C-banding (centric banding) (Arnason et al.,1980; Duffield and ChamberlinLea,1990; Stock,1981). The variants which are visualized with each of these methods seem to have no phenotypic effect and are inherited in a Mendelian fashion (Olson et al.,1983; Duffield and Chamberlin-Lea,1990).

Fluorescent R-banding has previously been used as a method for identifying chromosome heteromorphisms in Tursiops truncatus (Duffield and Wells,1991; Duffield and 
Chamberlin-Lea, 1990). R-banding is the staining technique of choice for analysis of cetacean chromosomes because it allows for simultaneous visualization of heteromorphic variants, as well as provides a distinct banding pattern which allows for pairing of homologous chromosomes (Duffield and Chamberlin-Lea,1990; Duffield et al.,1991). Q-banding does not produce differential staining of cetacean chromosomal variants and C-banding, which preferentially stains centromeric regions of chromosomes, does not produce a banding pattern to allow for the unequivocal pairing of homologues.

\section{Thesis Project: Matagorda Bay Tursiops Study}

In my study, fluorescent R-banding techniques were used to evaluate the chromosomal variants of thirty-six bottlenose dolphins captured and released off the central Texas coast, near Matagorda Bay. Large-scale die-offs of Tursiops had been noted in the months prior to beginning this capture-and-release study. This study was initiated in order to try and more clearly understand how bottlenose dolphin populations utilize the Matagorda Bay area. Due to the availability of blood samples from the animals, it was suggested that an extensive genetic study of the sampled population be undertaken. It was hoped 
that the combination of genetic and field observational data would allow for a more thorough understanding of the animals that make up the Matagorda Bay Tursiops population.

In this cytogenetic analysis of the 36 bottlenose dolphins, a distribution of fluorescent $R$-band variants was catalogued and used as a way to characterize the genetic structure of the Matagorda Bay Tursiops population. This distribution was also used to compare this group of animals with another Tursiops population residing in the Gulf of Mexico on the central west coast of Florida which had already been studied cytogenetically. Evaluations of maternity and paternity were made, as well as intrapopulation comparisons of variant frequencies among the animals sampled from Matagorda Bay. Three different methods of quantifying genetic differences between and within populations were assessed for their usefulness in evaluating potential genetic differences between groups of animals using chromosome heteromorphisms. Baseline levels for measuring cytogenetic differences between and among bottlenose dolphin populations were established for each test. It is hoped that this information will increase the understanding of how Tursiops utilize the Matagorda Bay area. 


\section{Materials and Methods}

\section{Matagorda Bay Tursiops Population}

Thirty-six bottlenose dolphins, sixteen females and twenty males, were captured and released near Matagorda Bay, Texas, during a two-week period of July, 1992. All thirty-six animals were tagged with dorsal fin roto-tags and thirty-five of the animals were simultaneously freeze-branded with identification numbers. Radio transmitters were affixed to ten of the dolphins to aid in locating the animals after they were released (Würsig and Lynn, 1993). Monitoring of the subject animals continued via photographic surveys, and by periodically tracking the animals through the use of radio-tagging, through 1993 .

At the time of capture, genders of the animals were ascertained and estimates of potential mother and calf pairs, were made based on proximal associations between animals. Estimates of the age of each animal were performed using tooth-aging methods (Hohn,1980; Hohn et al.,1989). The sex, identification, capture location and estimated age of each animal are given in Table 1 and Figure 1.

One group of animals, which were captured within the Northeastern region of the study area, were not resighted 
after the initial capture. These ten animals, nine of which were successfully cytogenetically analyzed, have been designated as the Northeast (NE) subgroup for the purposes of further genetic analysis. The remaining 26 animals, which comprise the Matagorda Bay sample population, are designated the southwest (SW) subgroup. Members of the NE group are indicated on Table 1 by a double asterisk.

\section{Chromosome Cultures}

Whole blood samples were obtained from each of the thirty-six bottlenose dolphins involved in the study. The blood was refrigerated at 4 degrees Celsius and shipped, via next-day air service, to Portland state University where it was used for the initiation of chromosome cultures. Three separate chromosome cultures were established for each animal sampled.

Chromosome preparations were made using a leukocyte protocol for cetaceans (Duffield \& Chamberlin-Lea, 1990). Approximately seven drops of whole blood (measured from a $1 \mathrm{ml}$ disposable serological pipette) were added to $4 \mathrm{ml}$ of RPMI 1640 media (Gibco) supplemented with 15\% fetal calf serum, 1\% penicillin-streptomycin and stimulated with various mitogenic agents. One culture from each individual (designated the PK culture) was supplemented 
with $0.05 \mathrm{ml}$ pokeweed mitogen. One sample was grown with 1\% phytohemaglutinin as a mitotic stimulant (designated the PHA culture), and a third culture was supplemented with both $1 \%$ pokeweed mitogen and $1 \%$ phytohemaglutinin (designated the PHA + PK culture).

All cultures were incubated at 36.0 degrees C for 96 hours prior to the addition of $0.05 \mathrm{ml}$ colcemid (Gibco). An additional sixteen hours of incubation at 36.0 degrees $C$ followed the colcemid treatment after which time the cultures were harvested. Cultures were centrifuged at $1000 \mathrm{rpm}$ for 10 minutes and then treated with $5.0 \mathrm{ml}$ $0.075 \mathrm{M} \mathrm{KCl}$ hypotonic solution for ten minutes. Cells were fixed and stored in a 3:1 ethanol:glacial acetic acid solution.

Metaphase chromosome spreads were initially located on microscope slides by standard staining with Giemsa. Slides were then destained in fixative solution and banded using a fluorescent $\mathrm{R}$-band technique employing both distamycin $A$ and chromomycin A-3 (Duffield and Chamberlin-Lea,1990; Sahar and Latt,1978;

Schweizer, 1980). Detailed protocols of blood culturing and harvesting techniques and $\mathrm{R}$-banding methods are presented in Appendix 1. Metaphase cells were located and photographed using TechPan 2415 (Kodak) film on a Zeiss epifluorescence microscope equipped with an 
ultraviolet light source. Film was developed using Diafine 2-step developer and cells were printed on Kodak and AGFA photographic paper.

\section{Chromosome Variant Analysis}

Metaphase chromosome spreads from each animal were banded, photographed, karyotyped and evaluated for heteromorphisms. When evaluating chromosomal variants, multiple cells were examined and compared to one another in order to distinguish between true variants and artifacts resulting from staining and photographic methods.

Variable regions were noted on eleven different chromosomes and each distinct variant was assigned a numerical value based on a scoring method previously used to evaluate Tursiops chromosome variants (Duffield and Chamberlin-Lea, 1990). Since heteromorphisms are not discrete entities but rather continuums of variation, the numerical assignments are used only to indicate major differences in the size or fluorescent intensity of the variable region.

\section{Statistical Analysis}

Three quantitative statistical methods were used to evaluate subpopulation structure, using cytogenetic variant analysis, within the Matagorda Bay population. 
These same statistical analyses were applied to the Matagorda Bay and Sarasota Tursiops populations in order to quantify the cytogenetic differences which exist between these two populations.

1. Population Equilibrium Estimates

a. Hardy-Weinberg equilibrium analysis

Variable regions on the 11 chromosomes which exhibit cytogenetic differences were tested to see if the variants present were in Hardy-Weinberg equilibrium. A population distribution of heteromorphism scores for each variable region for both Matagorda Bay and Sarasota populations was tested for Hardy-Weinberg equilibrium using the log-likelihood ratio (G-test) analysis. Gstatistics were applied to groups studied within the Matagorda Bay sample, as well as to test for differences between Matagorda Bay and a similar Tursiops population residing near Sarasota, Florida.

Calculation of G-statistics was performed using the following formula (from Zar, 1984):

$$
\begin{aligned}
& \mathrm{G}=4.60517\left[\Sigma f_{i} \log _{10} f_{i}-\Sigma f_{i} \log _{10} f_{e}\right] \\
& f_{i}=\text { observed values } \\
& f_{e}=\text { expected values }
\end{aligned}
$$

For the purpose of evaluating significance of difference from predictions of the Hardy-Weinberg 
equilibrium equation, three genotypic classes were used to group animals into sufficiently large data sets. These three classes were: 1) most common allele homozygotes; 2) most common allele heterozygotes; and 3 ) all other homozygotes and all other heterozygotes, grouped together.

b. Population Pooling

As a method to assess the presence or absence of subgroups from within the Matagorda Bay sample, a population pooling approach (Winans and Jones,1988) was undertaken. The basis of this approach is comparing the G-statistic values between two or more possible subgroups with the G-statistic values which are obtained by pooling the subgroups together. If the pooled population has Gstatistic values that are larger than those obtained in either or both subgroups, it may be indicative of genetic differentiation between the subgroups under investigation.

\section{Pair-Wise Similarity Coefficients}

Chromosomal variant sharing $(S)$ was determined in a series of pair-wise comparisons as the number of variants which were shared between any two dolphins. This similarity value, $s$, between any two individuals in the 
sample population was calculated (from Lehman et al.,1992) as :

$$
\mathrm{S}=2 \mathrm{n}_{\mathrm{xy}} /\left(\mathrm{n}_{\mathrm{x}}+\mathrm{n}_{\mathrm{y}}\right)
$$

$\mathrm{n}_{\mathrm{xy}}=$ number of variants shared between individuals $\mathrm{x}$ and $\mathrm{y}$ $\mathrm{n}_{\mathrm{x}}+\mathrm{n}_{\mathrm{y}}=$ total number of variants possessed by individuals $x$ and $y$, respectively

Use of this formula allowed for comparisons to be made between males and females by adjusting for differences in the number of variants compared. Males were scored for 29 variants (28 autosomal regions as well as the 'Y' chromosome), while females were scored only for autosomal variants.

Z-scores were used to test how far the similarity values (S) for suspected mother and calf pairs, identified from within the Matagorda Bay population, deviated from the mean $S$-value calculated for the population as a whole. Z-scores (from McClave and Dietrich, 1988) were calculated by subtracting the mean Svalue for the entire Matagorda Bay population from the Svalue calculated for the potential mother and calf. This value is then divided by the standard deviation for the average S-value of the Matagorda Bay population.

3. Nei Index for Measuring Allelic Frequency Differences

A third method of evaluating intrapopulation and interpopulation genetic differences was used to quantify 
the amount of difference in allelic frequencies between two groups of animals, using each chromosome variant as an allele. A similarity index (I), based on Nei's genetic distance (Nei and Tajima,1983), was calculated to measure the probability that two alleles, drawn at random, one from each population, would be identical. If two populations share identical variant frequencies, the similarity index will be 1.0. The larger the difference in frequency of alleles between the groups, the lower the index, and hence the probability, will be. The calculation of the similarity index (I) is as follows (from Mettler et al.,1988):

$$
\begin{aligned}
& I=j_{x y} / \sqrt{ } j_{x} j_{y} \\
& j_{x y}=\sum x_{i} y_{i} \text { where } x_{i} \text { is the frequency of an allele (the } \\
& \text { ith in population } x, \text { and } y_{i} \text { is } i t s \text { frequency in } \\
& \text { population } y \\
& j_{x}=\sum x^{2}{ }_{i}=\text { sum of squared allele frequencies in population } \\
& j_{y}=\sum y_{y}^{2} \text { sum of squared allele frequencies in population }
\end{aligned}
$$

\section{Results}

\section{Heteromorphism Analysis}

Thirty-five of the thirty-six animals had a sufficiently high mitotic index to allow for variant analysis. One animal in the sample population (FB527) was deemed a culture failure after no metaphase cells 
were found on seven slides examined. A total of 247 metaphase cells were karyotyped and analyzed in this study. The mean number of metaphase cells scored for variants, per animal, was 7.06. The minimum number of cells analyzed on an individual animal was three (FB517), while the maximum number of cells analyzed was thirteen (FB530 and RT412).

A total of 48 different variants (Figure 2), located on eleven different pairs of chromosomes, as well as a small marker chromosome, were identified in the Matagorda Bay population. Four chromosomes had variable regions in both the short (p) arm as well as in the long (q) arm. Variant scores for each animal were assigned by examining multiple cells from an individual and comparing those variants present to a set of standards derived from variants in this population and variants reported for the Sarasota bottlenose dolphin population (Duffield and Chamberlin-Lea,1991). A score was assigned to each homologue of a pair, creating a binomial value for each variable chromosome pair. Chromosomes 20 and 21 were also scored for the presence of satellites, indicated as an "S" after the numerical value. A complete listing of the variants identified in each animal is presented in Table 2. Appendix 2 presents a series of chromosome composite sheets. A representative cell from each of the 
Matagorda Bay study animals was chosen for these composite sheets and only those chromosomes which have variable regions are shown in the composites. These sheets were compiled and used to analyze the variant regions for each animal sampled in Matagorda Bay. Appendix 2 also presents a representative complete karyotype from an individual member of the Matagorda Bay Tursiops sample. The polymorphic variation found in the Matagorda Bay Tursiops sample population was extensive enough that no two animals within the study had an identical set of variant scores.

\section{Statistical Analysis}

I. Population Equilibrium Estimates

a. Hardy-Weinberg Equilibrium Analysis

1. Matagorda Bay

Variant (allele) frequencies and genotype distributions for the Matagorda Bay population, listed by chromosome region, are presented in Tables 3 and 4 . These observed genotype frequencies were compared to values predicted by the Hardy-Weinberg model and a Gstatistic was calculated to see if statistically significant differences existed between the two values.

When the Matagorda Bay population was evaluated for goodness-of-fit to values predicted by Hardy-Weinberg 
equilibrium, one variable region, 18p, deviated significantly $(p<0.05)$ from expected values (Table 5). A large number of heterozygous individuals was responsible for the skewing of the observed values. Further analysis of chromosome region $18 \mathrm{p}$ revealed that, when broken down into male and female subgroups (Table 6), the male population showed significant departure from expected Hardy-Weinberg values $(p<0.05)$ due to a large number of heterozygotes, while the female subgroup did not.

Because of the apparent discrepancy in genotype frequencies between males and females, identified in the evaluation of chromosome region $18 \mathrm{p}$, a subsequent analysis of equilibrium estimates for all variable chromosome regions was performed for male and female members of the Matagorda Bay population.

\section{Matagorda Bay Males and Females}

Males and females were treated as separate populations and allelic frequencies for each variant were calculated (Table 7). Each group, males and females, were tested to see if the variant and genotype frequencies were in close agreement with values predicted by Hardy-Weinberg equilibrium. At one locus, chromosome region 2q, the Matagorda Bay females differed significantly $(p<0.05)$ in genotype frequency from the 
values expected under Hardy-Weinberg rules. A large number of homozygotes led to this deviation. At a different locus, chromosome region 18p, the males showed a similar deviation from expected values, as mentioned above. In this case, a large number of heterozygotes led to the deviation of observed values from those which would be expected from an equilibrium population.

3. NE and $S W$ Subgroups Within Matagorda Bay Allelic frequencies, genotype frequencies and Gstatistics were also calculated and compared for the nine animals (NE group) who were not resighted after capture, versus the values calculated for the twenty-six animals (SW group) from within Matagorda Bay (Table 8). It was found that the NE group also had a statistically significant deviation from expected values at chromosome region 18p $(p<0.05)$. As with the evaluation of the Matagorda Bay male subgroup, a large number of heterozygous individuals at this locus lead to the discrepancy between observed and expected results.

4. Sarasota Population

When variant distributions from the previously reported sarasota population were tested for goodness-of- 
fit to Hardy-Weinberg equilibrium expectations, statistically significant deviations from expected values were found at two variable regions (Table 5). For both of these regions, $1 q$ and $2 p$, an increased number of homozygous individuals was responsible for the skewing of the observed frequencies from those expected in a population at equilibrium. A similar deviation, due to a large number of homozygotes, was detected in the Matagorda Bay female subgroup.

5. Matagorda Bay and Sarasota Pooled

When Matagorda Bay and Sarasota population samples were pooled and treated as a single breeding unit, three of fourteen variable regions showed statistically significant deviations $(p<0.05)$ from expected values (Table 5). Regions $1 \mathrm{q}, 2 \mathrm{p}$ and $4 \mathrm{p}$ all had an increased number of homozygous individuals. This number of discrepant regions is more than either the Matagorda Bay sample or the Sarasota sample showed when each was treated as a single population.

\section{b. Population Pooling}

G-statistics were also used to see if the genotype frequencies in a "pooled" population deviate farther from expected values than either or both of the individual 
populations which were combined to create the pooled group (Winans and Jones, 1988).

When the Matagorda Bay females and males were treated as individual populations, and G-statistic values were compared to those calculated for Matagorda Bay as a whole, four of fourteen regions (28.6\%) showed pooled values greater than either group treated alone (Table 7). Similarly, when the outgroup of nine individuals (NE group) from within Matagorda Bay were treated as their own population and compared to the frequencies calculated from the remaining twenty-six animals from the Matagorda Bay sample, 4 of 14 regions (28.6\%) were also found to have larger G-statistic values in the pooled group than in either subgroup (Table 8).

When Matagorda Bay and Sarasota populations were treated separately and then as a pooled population, seven of fourteen ( $50 \%$ ) variable regions had G-statistic values that were larger in the pooled population than in either individual population (Table 5).

II. Pair-Wise Similarity Coefficients (S)

A similarity value (S) was calculated to express the relative amount of variant sharing between any two individual animals. A mean S-value was calculated to assess the amount of variant sharing occurring within 
groups of animals. The mean S-values were then used to compare average variant sharing between selected groups of animals.

The S-values for any two individuals from the Matagorda Bay sample (Table 9) ranged from 0.276 to 0.862. Of 595 pair-wise comparisons made, the mean $S$ value was 0.582 . The standard deviation was 0.09 . A graph of the S-value distribution for the entire Matagorda Bay population is shown in Figure 3 .

Mean S-values were calculated for different groupings of animals selected from within the sample population. These calculations were used to see if any significant differences existed between subgroups. Mean similarity values were calculated to compare differences between all male animals and all female animals, as well as to compare average $\mathrm{S}$-values between the nine animals which were not resighted after the initial capture (the NE group) with those calculated for the twenty-six animals which were seen again after the capturing and tagging period (the SW group). None of the mean S-values calculated for the groupings showed substantial deviations from one another, or from the mean S-value calculated for the population as a whole. The mean Svalue for Matagorda Bay females was 0.577. The mean Svalue for Matagorda Bay males was 0.535. The mean S- 
value for the $N E$ group was 0.603 while the mean S-value for the SW animals was 0.574. A graph showing the distribution of the pairwise similarity values for the NE group as compared to the $\mathrm{SW}$ group is presented in Figure 4 .

III. Nei Index for Measuring Allelic Frequency Differences

Similarity index values were used to compare the allelic frequency differences between different groups of animals. Index values were calculated for the variants (used as alleles) for each individual chromosome region, as well as for the population as a whole, incorporating all 14 variable regions (Table 10).

When this method was applied to compare allelic frequencies from the Sarasota population with those in Matagorda Bay, similarity index values calculated for each variable region ranged from 0.73 to 1.00 . The combined index was 0.88 , which, when expressed as a probability, is interpreted as the chance of drawing identical alleles from the two different populations being only 0.88 as great as it would be if they were drawn from one population.

When Matagorda Bay was sub-divided into the nine animal (NE group) versus the twenty-six animal (SW group) subgroup, similarity index values ranged from 0.81 to 
1.00 with an overall similarity index value between the two groups of 0.95 . When the allelic frequencies among the Matagorda Bay males were compared to those found among the Matagorda Bay females, similarity index values range from 0.91 to 1.00 with an overall similarity index between these two subgroups of 0.97 .

\section{Evaluation of Maternity and Paternity}

A. Maternity Analysis

of the thirty-six animals involved in the study, five pairs of dolphins were thought to be mother and offspring pairs based on behavioral observations made during the capturing process. These potential mother and calf pairs, and the estimated ages of each, are shown in Figure 5 .

Chromosome heteromorphisms in cetaceans have been shown to be inherited in a stable manner and can therefore serve as a method for exclusion of a female as mother of a particular calf (Duffield and ChamberlinLea,1990). While the numerical values assigned to the individual variants of a potential mother and calf pair can be compared to one another to evaluate potential maternity (see Table 2), more frequently the evaluation is performed by simultaneously viewing multiple sets of cells from both the mother, as well as the suspected 
offspring. This direct visual comparison allows for detection of subtle differences which are not revealed by the numerical value.

Three adult females (FB503, FB511 and FB521) suspected of being the mothers of calves were excluded as mothers using chromosome variant analysis. All three animals had variants at at least one locus which were not similar to the variants identified in the assigned calf, positively excluding the adult female as mother of the calf. An illustration of the variant differences between the discrepant pairs is shown in Figure 6 .

One adult female (FB515) could not be excluded as the mother of calf FB517 on the basis of chromosomal variant inheritance due to the poor quality of cells analyzed in FB517. One pair, FB507 and FB509, had chromosome variants which were consistent with an inheritance pattern of mother-to-calf.

When the five sets of suspected mother-calf pairs were examined for similarity values (S), FB503 and FB508 had a similarity coefficient of 0.491 , less than the population mean and also below the 0.500 level which would be the minimum similarity value expected when calculated for a parent and offspring pair. The four remaining pairs of animals (FB507/FB509; FB511/FB513; FB515/FB517; FB521/FB520) ranged from 0.536 to 0.714 (see 
Table 11). An illustration showing the relationship between $S$-values for suspected mother-calf pairs, in relation to the distribution of $\mathrm{S}$-values for the entire Matagorda Bay population is shown in Figure 7 .

Z-scores were used to measure the distance of each mother-calf pair similarity coefficient from the average similarity value calculated for the entire Matagorda Bay population. Two of the potential parent-offspring pairs had negative $\mathrm{Z}$-scores, reflecting that they fall below the mean similarity value for the population. Two pairs have $\mathrm{z}$-scores between zero and one, indicative of their values falling within one standard deviation of the mean. The fifth pair, FB507 and FB509 have a $Z$-score of 1.47, indicating that this pair has a similarity coefficient greater than one standard deviation above the population average. A list of the Z-scores for the five suspected mother-calf pairs is shown in Table 11.

B. Paternity Analysis

Previous observational and genetic studies of captive Tursiops populations have shown that males over the age of 20 years typically sire the majority of calves born into captive breeding groups (Duffield and Wells, 1991). In the Matagorda Bay population, three males (FB516, FB530 and FB532) were estimated to be approximately 20 years old at the time of their capture. 
Of these, one (FB516) had an unusual combination of variants for three of the acrocentric chromosomes, being homozygous for a value of '1' at chromosome pairs 19, 20 and 21. Based on the frequencies of a '1' value for each of these acrocentric chromosomes in the sampled population, there is a $0.015 \%$ chance of an animal being homozygous for a 'I' allele at all three loci. He was excluded as a potential sire of all five calves in the Matagorda Bay study with this variant combination.

The other two adult males, FB530 and FB532, were also excluded as sires of the five calves based on their combinations of variants. Both of these males were part of a group of ten individuals not resighted after the initial capturing period. Furthermore, they were captured in a part of the study area where none of the calves were captured or subsequently observed.

\section{Marker Chromosome}

A small extra chromosome was found to be present in a majority of the cells examined from one animal, FB534, in the Matagorda Bay study. A composite set of FB534's variable chromosomes, including the small marker chromosome (labeled 'mar'), is found in Appendix 2. Eight cells out of eleven photographed and examined from FB534 had the extra chromosome present. 
No other animal in the Matagorda Bay sample was shown to have any supernumerary chromosomes present. FB534, the male with the marker chromosome, was estimated to be 4-6 years of age at the time of capture and therefore was too young to have sired any offspring.

\section{Discussion}

\section{Behavioral Observations of Sample Population}

In the Matagorda Bay study, ten individuals were radio-tagged and subsequently tracked for periods ranging from twelve to sixty days. Six of the ten radio-tagged animals stayed within an approximate twenty $\mathrm{km}$ radius area of where they were first caught. Four other tagged animals (FB501, FB502, FB504 and FB505) showed greater ranges. FB501, an adult female, showed the least amount of site fidelity, occasionally traveling $55 \mathrm{~km}$ over a twelve hour period to traverse her home range (Würsig and Lynn, 1993). Home ranges were found to overlap strongly for all animals in the study with the exception of the 10 animals (FB523-FB532) who were not resighted again after capture. In comparison, the entire sarasota Bay Tursiops population inhabits a home-range area approximately $40 \mathrm{~km}$ long (Scott et al.,1990).

Animals in the Matagorda Bay study who were resighted after the initial capture were not observed 
leaving the bay area to enter oceanic waters either for feeding or for other purposes. Similarly, at no time did any of the radio-tagged dolphins show evidence of leaving the confines of the bay system to swim in the open ocean. These observations allow for speculation that these animals are members of a resident, in-shore population, similar in structure and composition to the Sarasota Bay Tursiops population. The remaining ten animals that make up the Matagorda Bay sample were not resighted after the capturing process, so their use of ocean areas and neighboring in-shore areas is unknown.

Based on observational data collected during the study period, it was suspected that the Matagorda Bay area represented a major geographic area enclosing most of a breeding population. Some observations, such as noting that the animals did not appear to leave the bay system for any length of time, seemed to support this idea. Other observations, including the inability to resight one group of ten animals after the tagging procedure, seemed to suggest that the Matagorda Bay population was not necessarily closed to migration or that Matagorda Bay animals are members of a series of subpopulations with overlapping home regions. Genetic analysis of dolphins inhabiting this coastal region of 
the Gulf of Mexico provides additional information about the population structuring of Tursiops within this Bay.

\section{R-Banded Chromosome Variation as a Method for Comparing Populations}

Previous cytogenetic analysis of a Tursiops truncatus population residing near Sarasota, Florida, provided an out-group for evaluating the cytogenetic variation which existed within the Matagorda Bay population. These comparisons together set baseline values for future comparisons of intra- and interpopulation structuring of Tursiops in Matagorda Bay and throughout the Gulf of Mexico.

By treating each chromosome variant as an individual allele, population genetic analyses used to evaluate polymorphisms in populations can be applied to the cytogenetic data. Three different quantitative analyses were used to examine the cytogenetic information compiled for the Matagorda Bay and Sarasota animals.

The first method applied the concept of HardyWeinberg equilibrium, where the distribution of variants at each chromosome region were evaluated for compliance to Hardy-Weinberg equilibrium expected values. Populations of animals were evaluated both as separate groups and then as pooled populations. The relative size of deviation of observed from expected values (as 
measured by G-statistics) was used to estimate whether the pooled populations were similar to individual groups; pooled groups with larger G-values than individual groups, implies subgroup structure.

Secondly, a pair-wise similarity index was calculated to compare the relative amount of variants shared between any two animals. This method has most commonly been applied to DNA analyses as a method to compare band-sharing of DNA restriction fragments between animals in a population. Previous analysis of S-values applied to molecular studies have shown that large Svalues are indicative of first generation relatives (Bishof and Duffield,1994).

A third analytical method applied to the data gathered in this study involved the calculation of Nei Genetic Distance Similarity Index values to assess the "distance" of polymorphism differences between populations or subpopulations.

\section{a. Hardy-Weinberg Equilibrium Estimates}

Minkoff (1983) explains that if a population is divided into genetically separate subpopulations which mate randomly within themselves, each subpopulation can establish a Hardy-Weinberg equilibrated state. If the allelic frequencies from these subpopulations are pooled 
and treated as a single population, an excess number of homozygotes would be observed. This effect, called Wahlund's principle, may explain the observance of excess homozygous individuals found within populations.

When the Matagorda Bay and Sarasota samples were pooled and treated as a single population, three loci had G-scores indicating significantly different observed values from expected values $(p<0.05)$, with each loci deviating due to an excess number of homozygous individuals. These two populations, known to have different allelic frequencies and to be fairly geographically isolated, show an increased number of homozygous individuals when pooled and treated as a single population. The Wahlund's effect suggests that, indeed, these two areas represent separate populations.

With regard to within region sub-structure, when genotypic and allelic frequencies for chromosomal variants found in the Matagorda Bay and Sarasota populations were treated individually and compared to Hardy-Weinberg equilibrium expectations, most variable regions had G-scores which revealed no significant deviations of observed values from expected values $(p>0.05)$. However, for the Sarasota population, two regions, $1 \mathrm{q}$ and $2 \mathrm{p}$, had excessive numbers of homozygotes $(p<0.05)$. The Sarasota sample represents a population 
known to consist of multiple interacting subgroups and also appears to follow wahlund's principle.

A similar deviation from expected values, due to excessive numbers of homozygotes was described in the Matagorda Bay females for chromosome region $2 \mathrm{q}$, and may suggest that the Matagorda Bay female subgroup also consists of female members from two or more different groups that are inhabiting the same or overlapping home ranges in this area.

When animals from Matagorda Bay were evaluated as a population as a whole, divided into male/female subgroups, or as NE/SW subgroups, statistically significant deviations from expected Hardy-Weinberg values in these three cases were attributable to an increased number of heterozygous individuals. Such deviations may be due to migration of animals into and out of the Matagorda Bay area, with reproductive exchange, suggesting that multiple subgroups of animals inhabit this overall region. In previous studies of Tursiops populations, males have been shown to exhibit the least amount of site fidelity and may be responsible for a significant degree of reproductive exchange between subgroups (Duffield and Wells,1991).

b. Population Pooling 
To further assess whether this sampling of animals from Matagorda Bay was representative of a single interbreeding group, or made up of two or more subgroups, the Winans and Jones (1988) technique of comparing HardyWeinberg equilibrium in individual groups versus pooled expectations was applied. The pooling of allelic and genotype frequencies between Matagorda Bay and Sarasota populations was used as a standard to see how two geographically separated populations would 'react' when pooled. It also provided an important calibration of the amount of deviation to be found between populations for a comparison of the degree of subgroup difference within the Matagorda Bay "population".

Calculations revealed that at seven of fourteen loci (50\%), the pooled G-statistic values for Matagorda Bay and Sarasota exceed the individual G-statistic values for each population alone. Given the geographical separation of these two populations, this value may represent the maximum amount of dissimilarity which will be found between geographically separated populations inhabiting the Gulf of Mexico.

When a pooled population calculation was performed on Matagorda Bay males versus females compared to pooling the two groups, it was found that deviations from expected values, as measured by G-statistics, were larger 
at four of fourteen loci (28.6\%) for the pooled population over the individual male and female sets. Due to the nature of dolphin social interactions--i.e., the strong associations that are formed among female members and the male-only bands which are often present in populations--the male and female groups sampled from Matagorda Bay may indeed be representative of two or more neighboring subgroups.

Four of fourteen (28.6\%) G-values from the pooled population were larger than both individual G-values calculated for the NE versus SW groups. This provides further evidence for potential subgroup separation existing within the Matagorda Bay region. The degree of deviation of pooled values (male versus female and NE group versus SW group) however, suggests that the differences between the local subgroups are considerably less than between the geographically separated populations. This supports the interpretation that genetic exchange between these local subgroups is greater, as would be expected by their sharing of a home range, than between geographically separate populations.

c. Pair-Wise Similarity Coefficients

Similarity coefficients were calculated for all pairs of animals from within the Matagorda Bay sample. 
When average similarity values for males versus female comparisons were made, no substantial differences in values were noted. In addition, a mean S-value comparison made between the $\mathrm{NE}$ and $\mathrm{SW}$ subgroups also showed no substantial difference in values.

Similarity values were, however, useful for evaluating potential mother-calf pairs, as well as possible father-calf pairings. It has been suggested by previous studies, employing DNA techniques, that high similarity values may indicate first degree relatives. In the Matagorda Bay study, none of the mother-calf or father-calf pairs showed a substantially higher S-value than any other pairs of animals examined from within the population.

d. Nei Index for Measuring Allelic Frequency Differences The similarity index value, calculated to compare allelic frequencies between Matagorda Bay and Sarasota, was 0.88 . This value was smaller than either of the similarity index values calculated to compare the Matagorda Bay intrapopulation comparisons. The similarity index for males versus females was 0.97 and the index value for the NE versus SW subgroups was 0.95 . These values suggest that the subgroup separation characterizing the Matagorda Bay sample is not as great 
as the genetic separation found between Matagorda Bay and Sarasota. Such a finding is not unexpected, given the close proximity of the Matagorda Bay subgroups as compared to the large geographic distance which separates the Sarasota and Matagorda Bay resident groups, and it fits with the relative differences in pooled values found in the Hardy-Weinberg equilibrium population pooling approach. Furthermore, this finding suggests that the local subgroup differences are there, but at substantially reduced levels, as compared to values found between geographically separated populations.

e. Unique Variants

Identification of unique chromosomal variants also gives some idea of the amount of genetic differentiation separating any two groups of animals. An extreme example of the usefulness of this evaluation technique would be the discovery of a variant which is fixed in one subgroup (as in the capuchin monkey studied by Matayoshi et al.,1987) and not found at all in any other subgroups. Such an occurrence would be indicative that a subgroup of animals no longer interacts with neighboring groups.

Eight heteromorphisms identified in the study of chromosomal variants in Tursiops from Matagorda Bay were not present in the sarasota sample. Similarly, six 
variants which had previously been identified in the Sarasota Tursiops population samples were not found in the Matagorda Bay sample. Therefore, fourteen variants were found exclusively in one population or the other (Figure 8). None of these unique variants were found to be fixed in either population.

For the Matagorda Bay male versus female comparison, it was found that five variants were identified only in male members, while two other variants were seen only in females, yielding seven variants separating these two subgroups. The frequencies of each of these unique variants ranged from 0.025 to 0.10 . However, it is possible that each variant would be identified in an animal of each sex if a larger sampling of animals from the region was obtained.

Seven of 48 (14.6\%) of the chromosomal variants identified in Matagorda Bay were found only in the 26 animal (SW) subgroup. The frequencies for each of these variants were all relatively low, ranging from 0.02 to 0.08 , leading to speculation that these particular variants might be identified in the $\mathrm{NE}$ subgroup if a larger number of animals were to be sampled and evaluated. No variants were found to be exclusive to the NE group. 
The identification of unique variants in the Matagorda Bay subgroups lends further support to some degree of local subgroup population structure within the Matagorda Bay region. The number of unique variants identified within each Matagorda Bay subgroup is not as great as the number of variants which distinguish the Matagorda Bay animals from the Sarasota population. This is consistent with the idea that there is more genetic exchange occurring between local subgroups than between geographically separated populations.

Although it cannot be concluded, through cytogenetic variant analysis, that the $\mathrm{NE}$ group of nine animals not resighted after capture represents a separate population, it is likely that the animals sampled from the NE and SW regions of Matagorda Bay are, indeed, representative of separate subgroups. The analyses of mitochondrial DNA types from this same sample population have shown that these nine animals are, in fact, representative of a genetically separate group (Lenox, in preparation). If this group is genetically distinct from the remainder of the Matagorda Bay sample, the chromosomal variant frequencies between these two neighboring groups may be as similar as they are due to the migration of individuals and reproductive exchange between these subgroups. Further investigation of the degree of 
distinction between these two groups will require the sampling of substantially more animals from both suspected groups.

An extra marker chromosome was identified in one male $(2 n=45)$ sampled from the Matagorda Bay region. A structurally similar marker chromosome was previously identified in the resident dolphin community in the Sarasota area. It was shown to be inherited in a stable manner, as it was transmitted from mother to calf (Duffield and Wells,1991). Further banding studies of this chromosome revealed that it was a bi-satellited chromosome composed of two nuclear organizing regions (Duffield and Wells,1991).

Ten animals from the Sarasota community were found to have the supernumerary chromosome. Mitochondrial DNA studies conducted on the Sarasota animals who had the extra marker chromosome revealed that these animals were of three different mtDNA types, suggesting that the marker had been passed by males to females of different maternal lineages (Duffield and Wells, 1991).

The discovery of a marker chromosome in an animal residing near Matagorda Bay supports the idea of possible transmission of chromosome variants from one population to another throughout the entire Gulf of Mexico region. The resolution of whether this is due to movement of 
individual animals (probably males) between distant populations or the spread of variants from one local subgroup to another in a clinal fashion will require further field studies of dolphin populations in the Gulf of Mexico. FB534, the Matagorda Bay male with the marker chromosome, was a young male (4-6 years old) and was resighted only once after the initial capturing period.

\section{f. Evaluation of Mother/Calf and Father/Calf Pairs}

When five sets of suspected mother-calf pairs were evaluated using chromosomal variants, three pairs were directly excluded through identification of variants in the potential mother which were not found in the suspected offspring. Because chromosome variants are inherited in a Mendelian fashion, the non-identification of a variant in a calf precludes maternity.

In one pair of animals, the poor quality of cells analyzed in the calf did not allow for absolute exclusion of the potential mother, but the pair-wise S-value between this pair was low (0.536), suggestive of nonmaternity.

For the fifth set of suspected mother/calf pairs, the variants present were consistent with that of a mother-calf pair. This pair, FB507 and FB509, also had the highest similarity coefficient $(S=0.714)$ of the suspected mother-calf pairs. However, based on tooth- 
aging methods, FB507 (the suspected mother) was estimated to be 4 to 6 years of age at the time of capture, and FB509 was estimated to be three years of age. Since bottlenose dolphin females are thought to reach sexual maturity (puberty) at five to seven years of age, and reproductive maturity (characterized by attainment of full adult size and maintenance of regular estrus cycles) at seven to ten years of age (Schroeder, 1990), it would seem highly unlikely that FB507 and FB509 are in fact, a mother and calf pair. It is possible, given the high degree of variant similarity between these two individuals, that they are siblings or half-siblings. Other genetic methods, including DNA fingerprint analysis and protein electrophoresis analysis, might provide additional genetic information to further test this relationship.

The importance of using a variety of methods, genetic as well as observational, to study wild populations is emphasized by this mother-calf issue. Based on capture observations and association data collected during the study period, five pairs of animals were assumed to be mothers and calves (Würsig and Lynn, 1993). In three of five cases, the chromosomal data, however, did not confirm this, suggesting that 
other explanations of behavioral associations need to be formed.

When the three oldest males in the Matagorda Bay population were analyzed with respect to transmission of variants to the five suspected calves identified in the sample, all three males could be excluded from paternity of these calves on the basis of their variant combinations. Chromosome heteromorphism analysis is, therefore, also useful in investigating paternity within these social groups.

\section{Analysis of Techniques To Assess Genetic Differences}

This study has demonstrated that by calculating the number of chromosome variant regions which differ at a statistically significant level from values expected under the Hardy-Weinberg equilibrium law, and the magnitude of those discrepancies, two different population evaluations can be made. The first evaluation, identifying which variants are not within equilibrium expectations and interpreting why they are discrepant (i.e., too many heterozygous or homozygous individuals) can be used to assess general population structure. If multiple variable regions are found to be out of equilibrium status, due to an increased number of homozygous individuals, it may be indicative of a high 
degree of in-breeding, or alternatively, an indication that two separate groups have erroneously been treated as a single group and Wahlund's effect is in operation. If an increased number of heterozygous individuals are found, it may be that the sample population is not closed to immigration or emigration, and animals are freely and randomly mating with animals from neighboring regions.

The second evaluation of population structure addresses whether a sample population is made up of two or more separate subgroups by a comparison of "pooled" equilibrium values.

When Winans and Jones (1988) used a population "pooling" method on populations of Dall's porpoise to assess whether they had sampled from one interbreeding but spatially separated group of animals or from two isolated non-interacting groups of animals, there was no established standard of how large the differences between pooled and individual values would be for known isolated populations of animals. This was because this study was initiated on a group of animals which were previously not studied, either behaviorally or genetically. Winans and Jones (1988) concluded that, because 7 of 9 variable loci (77.7\%) studied had pooled values which exceeded those of each group when treated individually, the groups did not represent one interbreeding population. Because of the 
ability to compare chromosome heteromorphisms in both the Sarasota and Matagorda Bay populations with variation within the Matagorda Bay study, a scale has been developed by which to measure relative differences between populations and subpopulations.

Pair-wise similarity coefficients provide useful gauges for the determination of relatedness among any two animals, but they are not precise enough to discriminate between subgroups residing in adjacent regions. Groups of animals occupying neighboring territories with a significant exchange of chromosome variants will presumably exhibit relatively high similarity values between animals.

When chromosomal variants are treated as alleles, polymorphic analyses such as the Nei Similarity Index can be used to quantify the differences in chromosomal variants from one group to another. This method appears to be a valuable technique for assessing the degree of genetic difference between intra- and interpopulation comparisons. When the technique was applied to compare the Matagorda Bay population chromosomal variants to those identified in Sarasota population, a value of 0.88 was calculated. This value is smaller than both intrapopulation comparisons made from within Matagorda Bay. Such a finding would be expected since the 
Matagorda Bay/Sarasota comparison represents a comparison of two geographical isolated groups, while a subgroup comparison is made from within one localized region. Therefore, similarity index values based on chromosome heteromorphisms are useful for establishing a "scale" of the genetic differences between breeding groups and populations of bottlenose dolphins.

Using these three methods of analysis, it was found that the genetic differences existing between animals sampled from the Matagorda Bay region were less than differences that existed between Matagorda Bay and Sarasota, the two populations assumed to be the most genetically separate due to their large geographic isolation from each other. This result is not surprising since the Matagorda Bay subgroups, residing in close proximity to one another, are not obviously separated geographically from one another. These results underscore the fact that it is possible to detect genetically differing subgroups which occupy a single geographic location.

\section{Thesis Conclusions}

To date, no other cytogenetic studies have attempted to quantify the results of chromosome heteromorphism analysis in populations. Also, methods of quantifying 
genetic data generally applied to studies involving DNA fingerprinting, protein electrophoresis variability and mtDNA analysis have not previously been evaluated for their applicability to chromosome variant analysis. When combined with observational and behavioral data, analysis of chromosomal variants provides a means of assessing the overall structure of wild populations. Each of the quantitative analyses used in this study indicates that there is potential subgroup separation present in the Matagorda Bay population area. It is, therefore, likely that because the Matagorda Bay captures occurred in several different areas encompassing a larger local geographic region, rather than occurring at a single, centralized location, sampling of multiple subgroups occurred.

Cytogenetic analysis of 36 bottlenose dolphins from the Matagorda Bay area revealed that:

- The Matagorda Bay Tursiops population most likely does not represent a single breeding unit or population, but instead consists of subgroups within a larger, geographically dispersed Tursiops population. This population may be inclusive of several neighboring bays, or it may encompass the entire Gulf of Mexico. 
- Chromosomal variants not seen before in other Tursiops studies were found in Matagorda Bay. However, a number of variants were found in both Sarasota and Matagorda Bay populations, with no fixed variants found exclusively in either population. This may indicate that a series of local, but inter-mixing populations occurs with variants being transmitted from core area to core area via individual animals that do not maintain core site fidelity. It should be noted, however, that the sample populations from both Sarasota and Matagorda Bay most likely represent only in-shore forms of Tursiops. Due to the nature of the capturing process (i.e. having to locate and capture animals in water shallow enough for humans to stand in), the samples may not be indicative of more pelagic, possibly migratory, groups of dolphins that inhabit the deeper waters of the Gulf of Mexico. Therefore, the Matagorda Bay study area and the Sarasota Bay study area probably represent home-range situations of coastal Tursiops populations which are separated by numerous other Tursiops groups, each inhabiting their own stretch of Gulf of Mexico coastline. Adult male animals, the least likely members of a Tursiops population to maintain site 
fidelity, may travel from home-range to home-range, helping to transmit variants from one area to another. Females, as exemplified by animal FB501 who traveled up to $55 \mathrm{~km}$ in a 24-hour period, may also be responsible for transmitting some genetic data from one region to another. Further analysis of mtDNA may clarify the extent of this transmission.

- The importance of combining observational data with cytogenetic information is emphasized by the evaluation of mother and calf pairs in this study. Cytogenetic analysis allowed for the exclusion of three suspected mothers in predicted mother-calf pairings. In one other pairing, a relatively high similarity value was described and the inheritance of variants was consistent with that expected of a mother-calf pair. However, tooth-aging analysis suggests that this pair of animals may be siblings or other first degree relatives.

- All three analytical methods used to evaluate cytogenetic differentiation showed consistent results when applied to inter- and intrapopulation comparisons. When analyses were used to evaluate the differences between two known geographically separated groups, the 
results obtained consistently showed greater differences than when the same analyses were applied to groups taken from within the Matagorda Bay population. All three quantitative methods, therefore, proved valuable as methods for assessing cytogenetic data.

- These analyses suggest that future studies of Tursiops residing in the Matagorda Bay area should focus on sampling larger number of animals from locations flanking Matagorda Bay. By focusing on sampling animals from locations which are at least 55 $\mathrm{km}$ apart (a figure representing the farthest distance traveled by any single individual in this sample), the chances of sampling members of one subgroup or another exclusively, should increase. 


\section{REFERENCES}

Arnason, U. 1972. The role of chromosomal rearrangement in mammalian speciation with special reference to Cetacea and Pinnipedia. Hereditas 70:113-118.

Arnason, U. 1974. Comparative chromosome studies in Cetacea. Hereditas 77:1-36.

Arnason, U., Benirschke, K., Mead, J.G., and Nichols, W.W. 1977. Banded karyotypes of three whales: Mesoplodon europaeus, M. Carlhubbsi and Balaenoptera acutorostrata. Heredita $87: 189-200$.

Arnason, U., Lutley, R., and Sandhold, B. 1980. Banding studies of six killer whales: an account of $\mathrm{C}$-band polymorphism and G-band patterns. Cytogenetics Cell Genet. $28: 71-78$.

Arnason, U. 1981. Banding studies on the gray and sperm whale karyotype. Hereditas 95:277-281.

Baker, C.S., Gilbert, D.A., Weinrich, M.T., Lambertsen, R., Calambokidis, J., McArdle, B., Chambers, G.K. and O'Brien, S.J. 1993. Population characteristics of DNA fingerprints in humpback whales (Megaptera novaeangliae). Journal of Heredity 84:281-290.

Bigg, M.A. 1982. An assessment of killer whale (Orcinus orca) stocks off Vancouver Island, British Columbia. Reports of the International Whaling commission. 32:655666 .

Bigg, M.A., Olesiuk, P.F., Ellis, G.M., Ford, J.K.B. and Balcomb II', K.C. 1990. Social organization and genealogy of resident killer whales (Orcinus orca) in the coastal waters of British Columbia and Washington state. Report, International whaling commission (special issue) 12:383405 .

Bischof, L.L. and Duffield, D.A. 1994. Relatedness estimation of captive Asian elephants (Elephas maximas) by DNA fingerprinting. Zoo Biology. 13:77-82.

Danielsdòttir, A.K., Duke, E.J., Joyce, P., and Arnason, A. 1991. Preliminary studies on genetic variation at enzyme loci in fin whales (Balaenoptera physalus) and sei whales (Balaenoptera borealis) from the North Atlantic. In: Genetic Ecology of Whales and Dolphins, Hoelzel, A.R., ed. Cambridge: International whaling Commission. 
Darling, J .D., Nicklin, C., Norris, K.S., Whitehead, H., and Würsig, B. 1995 (Authors). Whales, Dolphins and Porpoises. National Geographic Society, Washington, D.C.

Davis, K.M., Smith, S.A., and Greenbaum, I.F. 1986. Evolutionary implications of chromosomal polymorphisms in Peromyscus boylii from southwestern Mexico. Evolution 40 (3) : 645-649.

Duffield, D.A., 1977. Phylokaryotypic Evaluation of the Cetacea. Ph.D. Dissertation. University of California, Los Angeles.

Duffield, D.A., 1982. Indian River Tursiops: genetic studies. In: Live Capture, Marking and Resighting of Bottlenose Dolphins, Tursiops truncatus. Rept. NMFS contract NA80-GA-C-00063: 312-324.

Duffield, D.A., Ridgway S.H. and Cornell, L.H. 1983. Hematology distinguishes coastal and offshore forms of dolphins (Tursiops). Can. J. Zoology. 61(4):930-933.

Duffield, D.A., 1986. Orcinus orca: taxonomy and evolution-cytogenetics and population structure. In: Behavioral Biology of Killer Whales. Lockhard, J., Kirkevold, B., eds. New York:Alan R. Liss. 19-33.

Duffield, D.A. and Wells, R.S. 1986. Population structure of bottlenose dolphins: (2) Genetic studies of dolphins along the central wast coast of Florida. In: Population Structure of Bottlenose Dolphins, Wells, R.S., ed. NMFS Technical Report 45-WCNF-5-00366.

Duffield, D.A. and Chamberlin-Lea, J. 1990. Use of chromosome heteromorphisms and hemoglobins in studies of bottlenose dolphin populations and paternities. In: The Bottlenose Dolphin, Leatherwood and Reeves, eds. Orlando: Academic Press; 609-620.

Duffield, D.A., Chamberlin-Lea, J., Sweeney, J., Odell, D.K., Asper, E.D. and Gilmartin, W.G. 1991. Use of corneal cell culture for R-band chromosome studies on stranded cetaceans. In: Marine Mammal strandings. NOAA Technical Report. Reynolds, J.E. and Odell, D.K., eds. NMFS $88: 91-100$.

Duffield, D.A. and Wells, R.S. 1991. The combined application of chromosome, protein and molecular data for the investigation of social unit structure and dynamics in Tursiops truncatus. Rep. Int. Whaling Comm. Spec. Issue No. 13. pp. 155-169. 
Duffield-Kulu, D. 1972. Evolution and cytogenetics. In: Mammals of the Sea: Biology and Medicine. Ridgway, ed. Thomas, Ill.; 503-526.

Hersh, S.L. and Duffield, D.A. 1990. Distinction of Northwestern Atlantic offshore and coastal bottlenose dolphins based on hemoglobin profile and morphometry. In: The Bottlenose Dolphin, Leatherwood and Reeves, eds. Orlando: Academic Press; 129-142.

Hoelzel, A. R., and Dover, G.A. 1991. Genetic differentiation between sympatric killer whale populations. Heredity $66: 191-195$.

Hohn, A.A. 1980. Age determination and age-related factors in the teeth of western north Atlantic bottlenose dolphins. Sci. Repts. Whales Res. Inst. 32:39-66.

Hohn, A.A., Scott, M.D., Wells, R.S., Irvine, A.B., and Sweeney, J.C. 1989. Growth layers in teeth from knownage, free-ranging bottlenose dolphins. Mar. Mam. Sci. $5(4): 315-342$.

Irvine, A.B., Scott, M.D., Wells, R.S., and Kaufman, J.H. 1981. Movements and activites of the Atlantic bottlenose dolphin, Tursiops truncatus, near Sarasota, Florida. Fish. Bull. U.S. 79:671-688.

Lambertsen, R.H. and Duffield, D.A. 1987. Biopsy studies of the humpback whale, Magaptera novaeanglieae. MNFS and International whaling comm. Tech. Report.

Lehman, N., Clarkson, P., Mech, L.D., Meier, T.J. and Wayne, R.K. 1992. A study of the genetic relationships within and among wolf packs using DNA fingerprinting and mitochondrial DNA. Behav. Eco. Sociobiol. 30:83-94.

Magenis, R.E., Overton, K.M., Chamberlin, J., Brady, T., and Lovrien, E.W. 1977. Parental origin of the extra chromosome in Down's syndrome. Hum Genet 37:7-16.

Magenis, R.E. and Toth-Fejel, S. 1992. Cytogenetic comparison between Prader-Willi and Angelman syndromes. In: Prader-Willi Syndrome (S.B. Cassidy, ed.). SpringerVerlag publisher, 1992.

Matayoshi, T., Seuànez, H.N., Nasazzi, N., Nagle, C. Armada, J.L., Freitas, L., Alves, G., Barroso, C.M., and Howlin, E. 1987. Heterochromatic variantion in Cebus 
apella (Cebidae, Platyrrhini) of different geographic regions. Cytogenet. Cell Genet. 44:158-162.

MCClave J.T. and Dietrich, F.H. 1988. Statistics, Fouth edition. Dellen Publishing Company.

Mettler, L.E., Gregg, T.G., and Schaffer, H.E. 1988. Population Genetics and Evolution, Second Edition. Prentice Hall, New Jersey.

Minkoff, E.C. 1983. Evolutionary Biology. Addison-Wesley Publishing Company.

Müller, H., Klinger, H.P. and Glasser, M. 1975. Chromosome polymorphism in a human newborn population: II. Potentials of polymorphic chromosome variants for characterizing the idiogram of an individual. Cytogenet. Cell Genet. 15:239-255.

Nei, M., and Tajima, F. 1983. Maximum likelihood estimation of the number of nucliotide substitutions from restriction sites data. Genetics 105:207-217.

Olson, S.B., Magenis, R.E., Rowe, S.I. and Lovrien, E. W. 1983. Chromosome heteromorphism analysis in cases of disputed paternity. American Journal of Medical Genetics. $15: 47-55$.

Olson, S.B., Magenis, R.E. and Lovrien, E.W. 1986. Human chromosome variantion: The discriminatory power of $Q$-band heteromorphism (variant) analysis in distinguishing between individuals, with specific application to cases of questionable paternity. Am. J. Human Genetics. 38:235252 .

Ross, G.J.B. and Cockcroft, V.G. 1990. Comments on Australian bottlenose dolphins and the taxonomic status of Tursiops aduncus (Ehrenberg, 1832). In: The Bottlenose Dolphin, Leatherwood and Reeves, eds. Orlando: Academic Press; 101-128.

Sahar, E., and Latt, S.A. 1978. Enhancement of the banding patterns in human metaphase chromosomes by energy transfer. Proc. Natl. Acad. Sci. U.S.A. $75(11): 5650-5654$.

Schroeder, J.P. 1990. Breeding bottlenose dolphins in captivity. In: The Bottlenose Dolphin, Leatherwood and Reeves, eds. Orlando:Academic Press; 435-446. 
Schweitzer, D. 1980. Simultaneous fluorescent staining of $\mathrm{R}$-bands and specific heterochromatic regions (DA-DAPI) bands in human chromosomes. Cytogenetic Cell Genet. $27: 190-193$.

Scott, M.D. and Chivers, S.J. 1990. Distribution and herd structure of bottlenose dolphins in the Eastern tropical Pacific Ocean. In: The Bottlenose Dolphin, Leatherwood and Reeves, eds. Orlando: Academic Press; 387-402.

Scott, M.D., Wells, R.S. and Irvine, A.B. 1990. A longterm study of bottlenose dolphins on the West coast of Florida. In: The Bottlenose Dolphin, Leatherwood and Reeves, eds. Orlando: Academic Press; 235-244.

Shane, S.H., Wells, R.S. and Würsig, B. 1986. Ecology, behavior, and social organization of the bottlenose dolphin: A review. Mar. Mamm. Sci. 2:34-63.

Stevens, T.A., Duffield, D.A., Asper, E.D., Hewlett, K.G., Bolz, A., Gage, L.J., and Bossart, G.D. 1989. Preliminary findings of restriction freagment differences in mitochondrial DNA among killer whales (Orcinus orca). Can. Journal of Zoology. $67(10): 2592-5$.

Stock, A.D. 1981. Chromosomal variation and constitutive heterochromatin in three porpoise species (genus Stenella). Cytogenet. Cell Genet. 31:91-100.

Van Waerebeek, K., Reyes, J.C., Read, A.J., McKinnon, J.S. 1990. Preliminary observations of bottlenose dolphins from the pacific coast of South America. In: The Bottlenose Dolphin, Leatherwood and Reeves, eds. Orlando: Academic Press; 143-154.

Wells, R.S., Irvine, A.B., and Scott, M.D. 1980. Social ecology of inshore odontocetes. In: Cetacean behavior: mechanisms and functions, Herman, L.M., ed. New York: John Wiley and Sons.

Wells, R.S., Scott, M.D. and Irvine, A.B. 1987. The social structure of free-ranging bottlenose dolphins. In: Current mammalogy, Genoways, H. ed. Vol. 1:247-305.

Wells, R.S. 1991. The role of long-term study in understanding the social structure of a bottlenose dolphin community. In: Dolphin Societies, Pryor and Norris, eds. University of California Press. 
Winans, G.A. and Jones, L.J. 1988. Electrophoretic variabliltiy in Dall's porpoise (Phocoenoides dalli) in the North Pacific Ocean and Bering Sea. J. Mamm. $69(1): 14-21$.

Würsig, B. and Harris, G. 1990. Site and association fidelity in bottlenose dolphins off Argentina. In: The Bottlenose Dolphin, Leatherwood and Reeves, eds. Orlando: Academic Press; 361-365.

Würsig, B. and Lynn, S.K. 1993. Movements and site fidelity patterns of bottlenose dolphins on the central Texas coast: A report to the National Marine Fisheries Service, South East fisheries center, Miami, Florida.

Zar, J.H. 1984. Biostatistical Analysis, Second edition. Prentice-Hall. 


\section{Blood Culture Procedure}

1. Three to five mls. sodium heparinized whole blood are obtained from each dolphin to be studied.

2. Seven drops from a pasteur pipette of whole blood are added to each of three tubes (labelled PHA, PK and $\mathrm{PK}+\mathrm{PHA}$ ) containing four mls. of RPMI 1640 culture media supplemented with $15 \%$ fetal calf serum, $1 \%$ penicillinstreptomycin and either $0.05 \mathrm{ml}$ phytohemaglutinin (PHA culture), $0.05 \mathrm{ml}$ pokeweed (PK culture) or $0.05 \mathrm{ml}$ phytohemaglutinin and $0.05 \mathrm{ml}$ pokeweed (PK+PHA culture).

3. The cultures are incubated 36.0 degrees $C$ for 96 hours.

4. Sixteen hours prior to harvest, $0.05 \mathrm{mls}$ colcemid (Gibco) are added to each culture.

\section{References}

This method adapted from Blood Culture Procedure protocols at Dr. Debbie Duffield's laboratory at Portland State University and the Oregon Health Sciences University Clinical Cytogenetics Laboratory. 


\section{Blood Harvest Procedure}

1. Centrifuge each culture, after sixteen hour exposure to colcemid, for ten minutes at $1000 \mathrm{rpm}$; remove supernatent.

2. Add five mls. of $0.075 \mathrm{M} \mathrm{KCl}^{*}$ to each tube and resuspend cell pellet; centrifuge immediately for ten minutes at $1000 \mathrm{rpm}$.

3. Remove all but $0.5 \mathrm{Cc}$ of supernatent and resuspend pellet in remaining supernatent with a pasteur pipette. Add two mls. of fixative ( $3: 1$ ethanol:glacial acetic acid) and gently but rapidly mix with the cell suspension. When this is accomplished, add another two mls. of fixative, mix well and centrifuge for ten minutes at $1000 \mathrm{rpm}$.

4. After this last centrifugation, dilute the cell pellet with fresh fixative and make slides.

References

This method adapted from Blood Harvest Procedure protocols at Dr. Debbie Duffield's laboratory at Portland State University and the Oregon Health Sciences University Clinical Cytogenetics Laboratory.

$$
\text { *0.075 M KCl=5.59 g/L }
$$


Dye Solutions:

Buffer: Dilute $50 \mathrm{mls}$. of McIlvane's buffer, $\mathrm{pH} 7.0$, with $50 \mathrm{mls}$. of distilled water and add $0.102 \mathrm{~g}$ $\mathrm{MgCl}_{2} \cdot 6 \mathrm{H}_{2} \mathrm{O}$ for a final concentration of $5 \mathrm{mM}$.

Chromomycin $\mathrm{A}_{3}\left(\mathrm{CA}_{3}\right): \mathrm{A} 0.5 \mathrm{mg} / \mathrm{ml}$ solution of chromomycin A3 is made up in the above buffer.

Distamycin A (DA): A $0.1 \mathrm{mg} / \mathrm{ml}$ solution is made up in the above buffer.

1. Place 5 drops of Chromomycin $A_{3}$ on slide and add coverslip. Keep slide in the dark for twenty minutes.

2. Rinse slide with McIlvane's buffer and shake off excess.

3. Place 5 drops of Distamycin A onto slide and add a coverslip. Keep in the dark for 5 minutes.

4. Again, rinse slide, blow dry with jet of air and mount a clean coverslip with glycerol.

5. Examine the slide on a fluorescent microscope using a 490 excitor, 510 reflector and $520 \mathrm{~nm}$ barrier filters or their equivalents.

This method adapted from R-Banding Procedure protocols at Dr. Debbie Duffield's laboratory at Portland state University and the Oregon Health Sciences University Clinical Cytogenetics Laboratory. 


\section{R-Band Reagents:}

Chromomycin A3:

Stock solution is $2.0 \mathrm{mg} / \mathrm{ml}$

To arrive at $4.0 \mathrm{mls}$. of $0.5 \mathrm{mg} / \mathrm{ml}$ :

1. $0 \mathrm{ml} \mathrm{CA}$

$3.0 \mathrm{mls}$. MCIlvane's buffer (working solution with $\mathrm{MgCl} 2$ )

Distamycin A:

Dissolve $0.2 \mathrm{mg}$ Distamycin A in 2-3 drops methanol.

Add $2.0 \mathrm{mls}$. McIlvane's buffer (with MgCl2).

\section{MCIIvane's Buffer:}

Solution $A$ :

0.2 M dibasic sodium phosphate

Made by dissolving $28.38 \mathrm{~g}$ into $1.0 \mathrm{~L}$ deionized water

Solution $B$ :

0.1 M citric acid

Made by dissolving $21.01 \mathrm{~g}$ into $1.0 \mathrm{~L}$ deionized water

Stock Solution-MCIlvane's Buffer ( $\mathrm{pH} 7.0$ ):

Combine $164.7 \mathrm{mls}$. of solution $A$ with $35.3 \mathrm{mls}$. solution $B$.

Working Solution-McIlvane's Buffer:

Combine $50.0 \mathrm{mls}$. stock solution with $50.0 \mathrm{mls}$. deionized water and add $0.102 \mathrm{~g} \mathrm{MgCl}_{2} \cdot 6 \mathrm{H}_{2} \mathrm{O}$ for a final concentration of $5 \mathrm{mM}$. 
APPENDIX 2

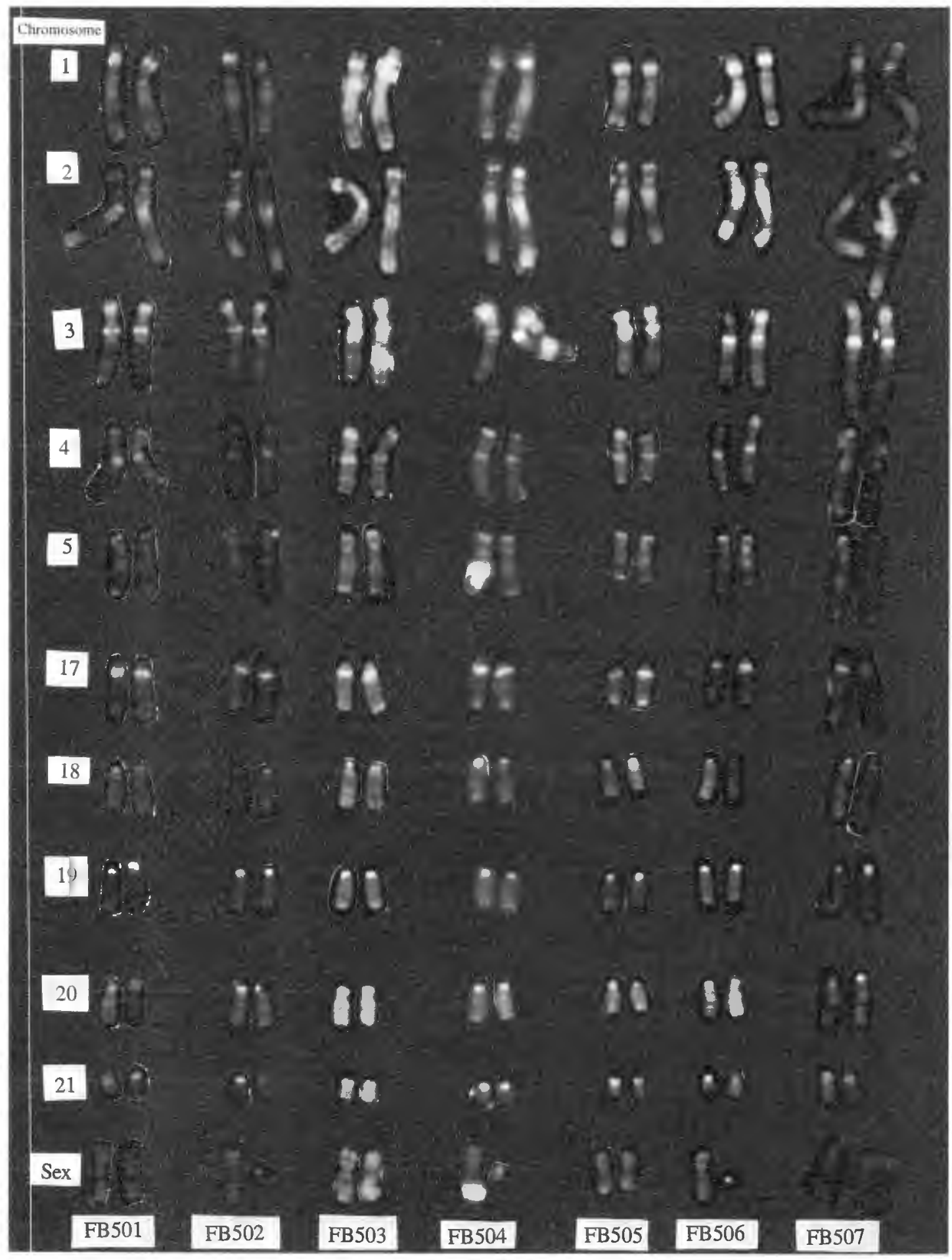




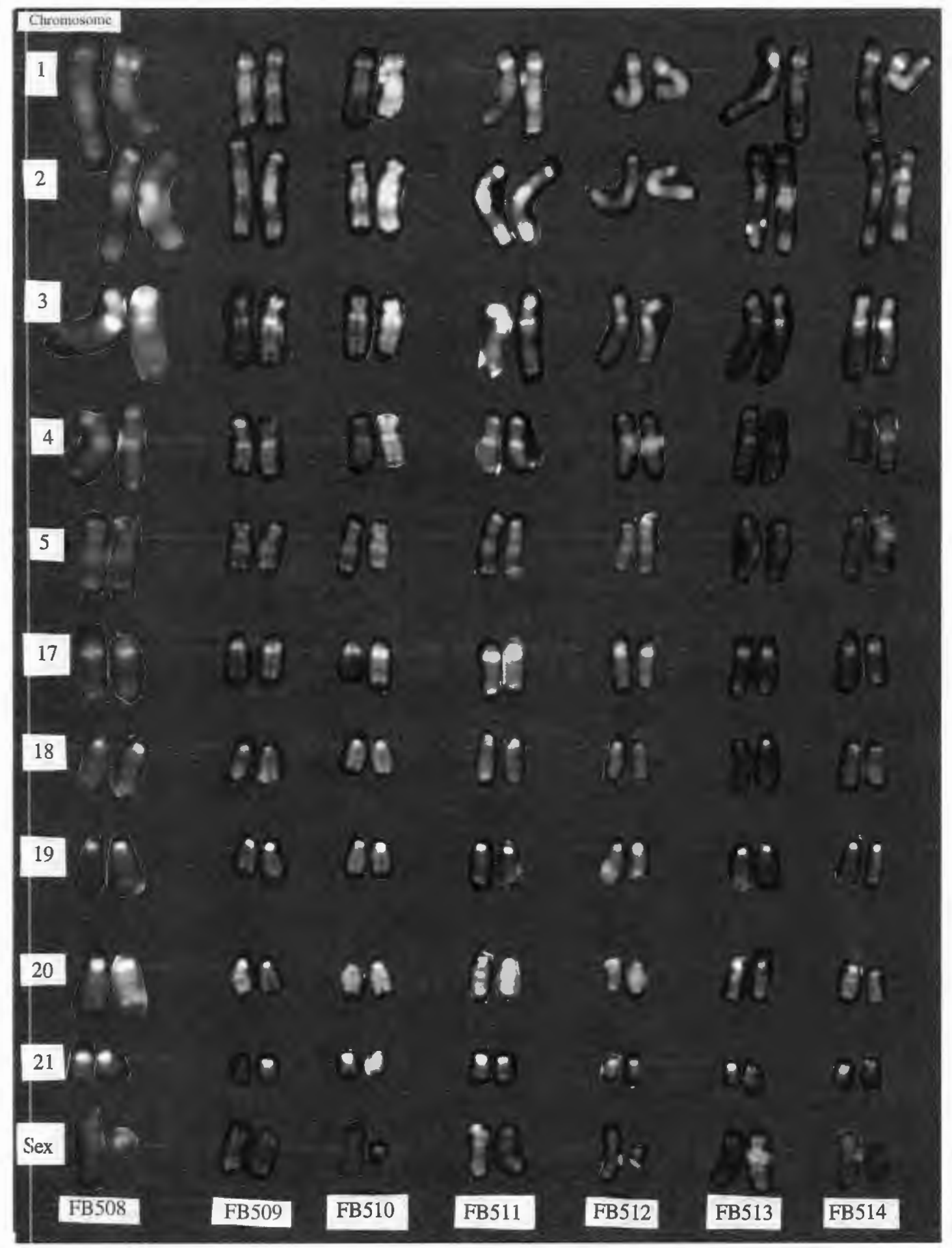




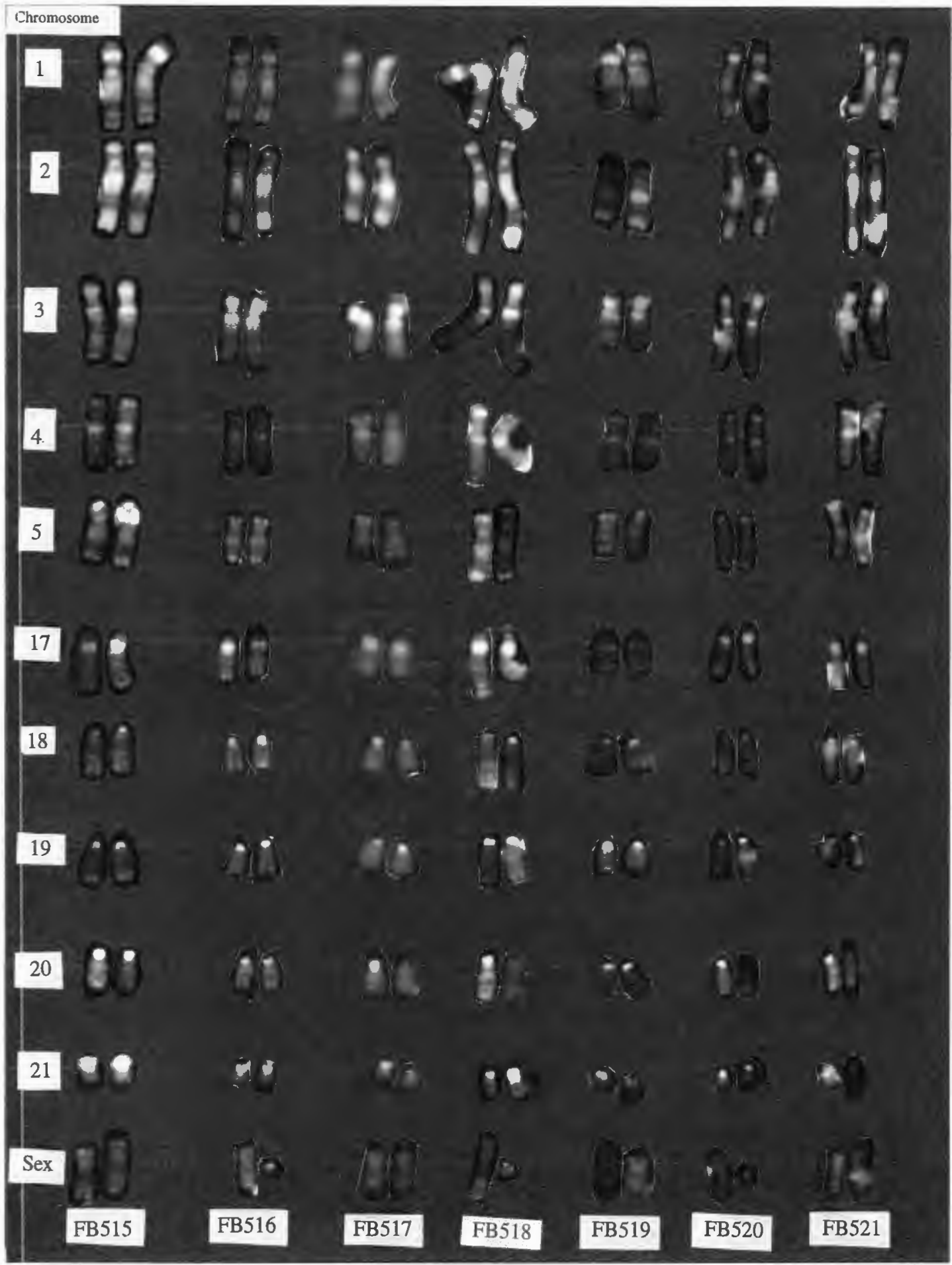




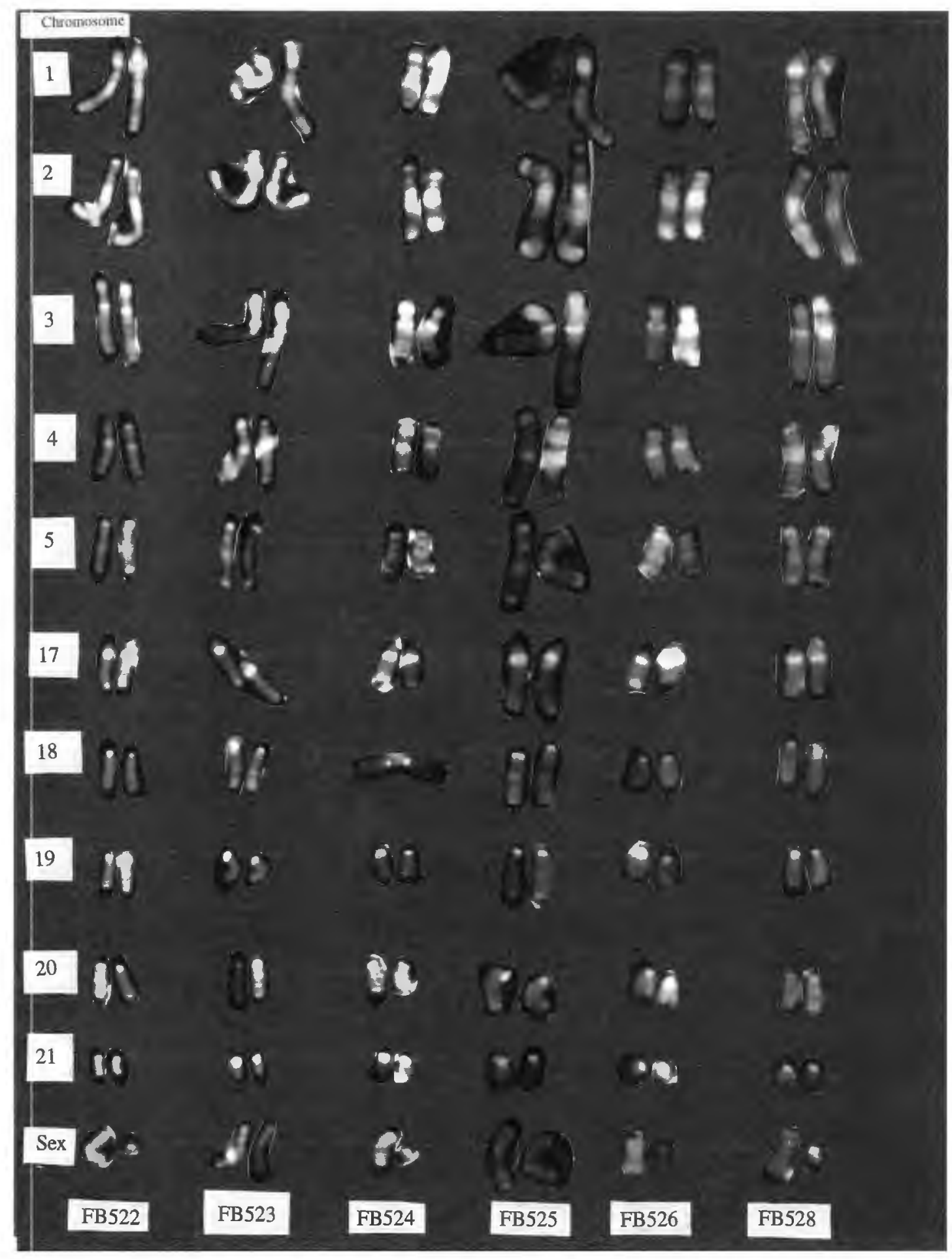




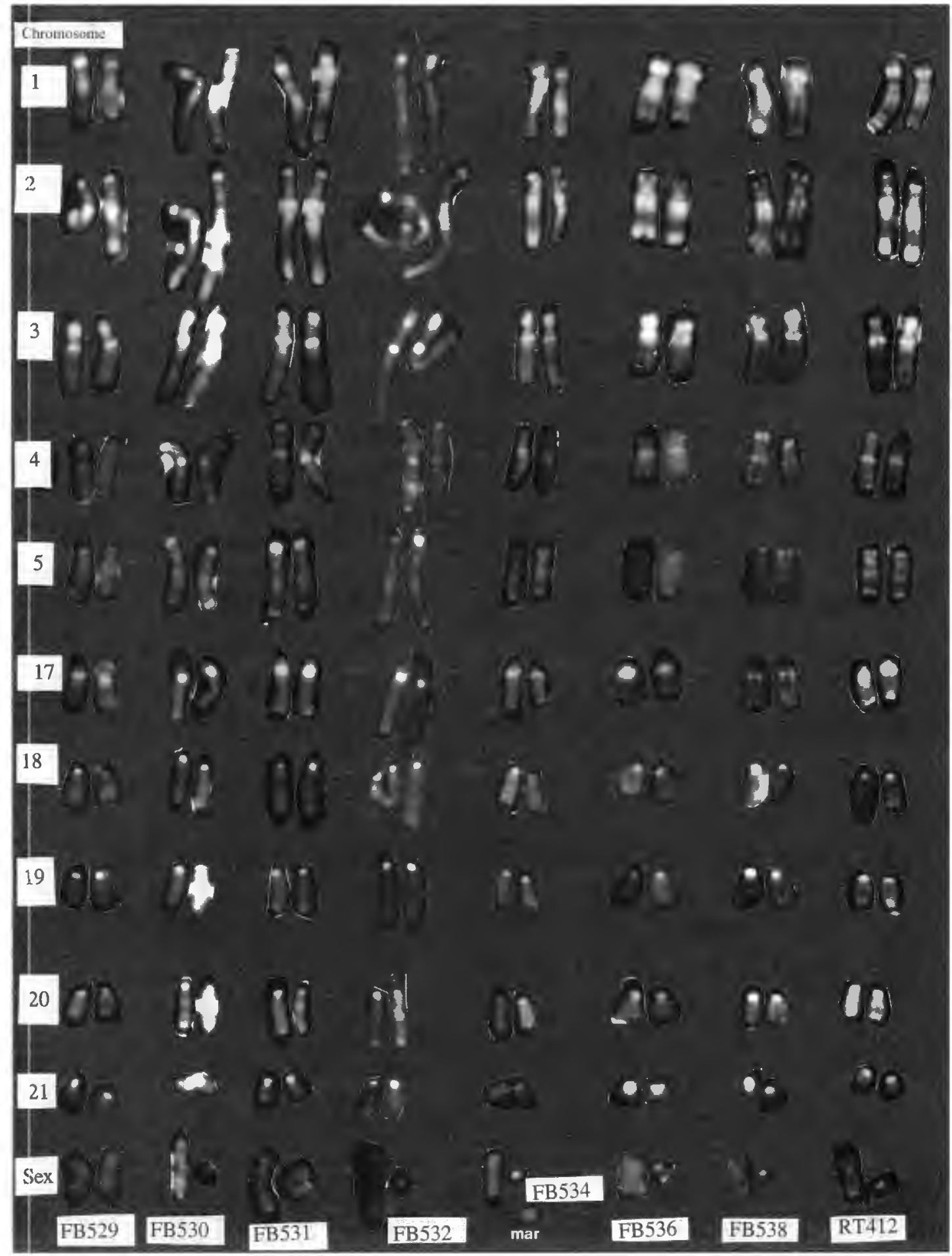




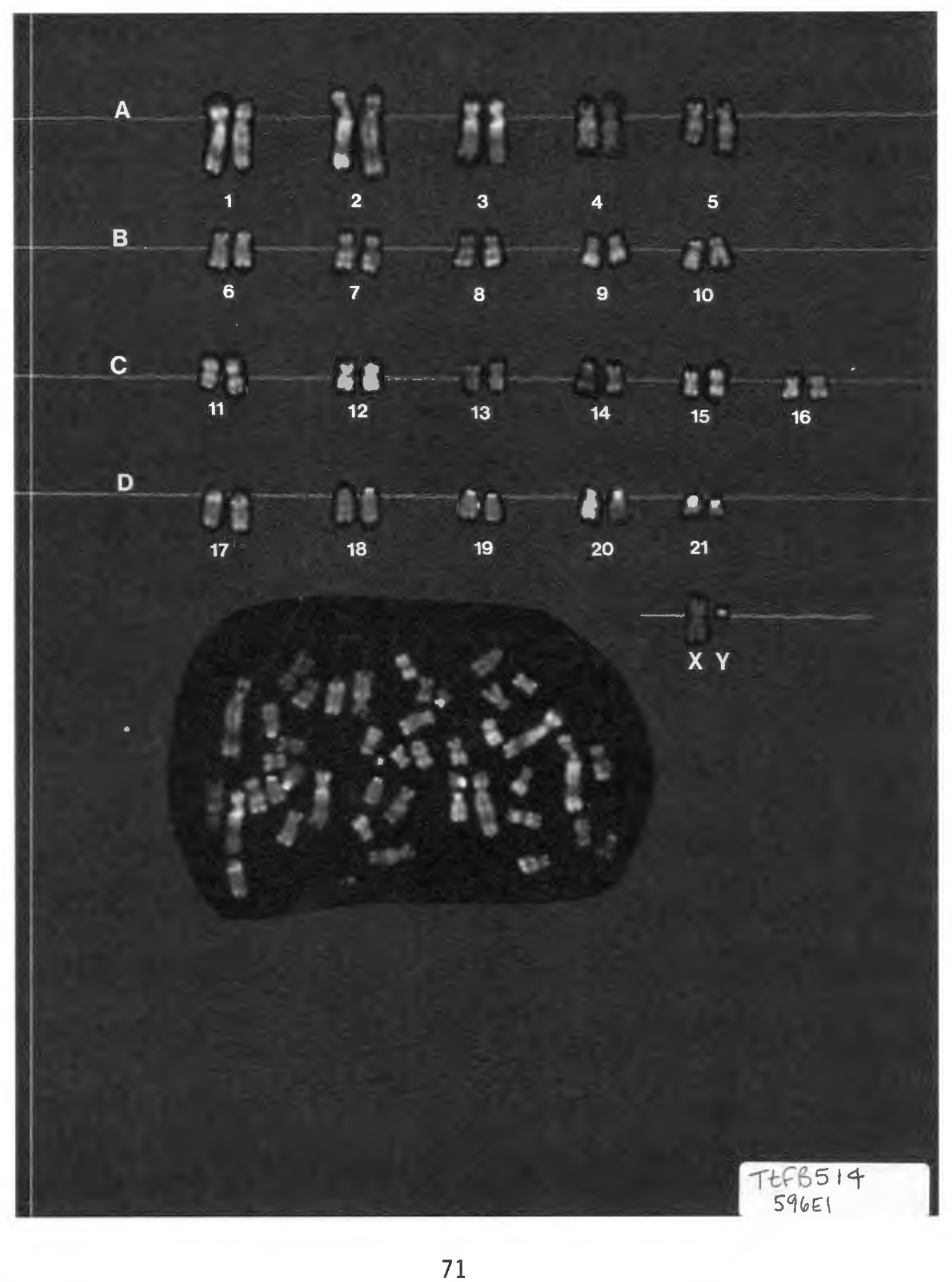


Table 1: Summary information of Matagorda Bay Animals

\begin{tabular}{|c|c|c|c|c|}
\hline Name & Sex & $\begin{array}{l}\text { Age } \\
\text { (years) }\end{array}$ & $\begin{array}{l}\text { Capture } \\
\text { location }\end{array}$ & $\begin{array}{l}\text { Date of } \\
\text { Capture }\end{array}$ \\
\hline FB501 & Female & $12-20$ & $f$ & $7 / 10 / 92$ \\
\hline FB502 & Male & 10 & $j$ & $7 / 9 / 92$ \\
\hline FB503 & Female & $10-12$ & 9 & $7 / 10 / 92$ \\
\hline FB504 & Male & $10-12$ & $j$ & $7 / 9 / 92$ \\
\hline FB505 & Female & $6-8$ & $\mathrm{~m}$ & $7 / 11 / 92$ \\
\hline FB506 & Male & 8 & $\mathrm{k}$ & $7 / 9 / 92$ \\
\hline FB507 & Female & $4-6$ & 1 & $7 / 11 / 92$ \\
\hline FB508 & Male & 2 & $g$ & $7 / 10 / 92$ \\
\hline FB509 & Female & 3 & 1 & $7 / 11 / 92$ \\
\hline FB510 & Male & 2 & 1 & $7 / 11 / 92$ \\
\hline FB511 & Female & $12-20$ & 9 & $7 / 12 / 92$ \\
\hline FB512 & Male & $4-6$ & 1 & $7 / 11 / 92$ \\
\hline FB513 & Female & 1 & 9 & $7 / 12 / 92$ \\
\hline FB514 & Male & 12 & 9 & $7 / 14 / 92$ \\
\hline FB515 & Female & $8-10$ & g & $7 / 14 / 92$ \\
\hline FB516 & Male & 20 & $i$ & $7 / 14 / 92$ \\
\hline FB517 & Female & 2 & 9 & $7 / 14 / 92$ \\
\hline FB518 & Male & 8 & $\mathrm{~h}$ & $7 / 15 / 92$ \\
\hline FB519 & Female & $8-10$ & $i$ & $7 / 14 / 92$ \\
\hline FB520 & Male & 2 & $\mathrm{~h}$ & $7 / 15 / 92$ \\
\hline FB521 & Female & $6-8$ & $\mathrm{~h}$ & $7 / 15 / 92$ \\
\hline FB522 & Male & $5-7$ & e & $7 / 17 / 92$ \\
\hline FB523* * & Female & $20-40$ & $\mathrm{~b}$ & $7 / 17 / 92$ \\
\hline FB524** & Male & $5-7$ & $d$ & $7 / 17 / 92$ \\
\hline FB525* * & Female & $3-4$ & $\mathrm{~b}$ & $7 / 17 / 92$ \\
\hline FB526** & Male & $6-8$ & $\mathrm{~d}$ & $7 / 17 / 92$ \\
\hline FB52 7 * * & Female & $6-8$ & $b$ & $7 / 17 / 92$ \\
\hline FB528* * & Male & $3-5$ & $d$ & $7 / 17 / 92$ \\
\hline FB529* * & Female & 4 & C & $7 / 18 / 92$ \\
\hline FB530* * & Male & $20-40$ & $a$ & $7 / 18 / 92$ \\
\hline FB531* * & Female & $3-4$ & C & $7 / 18 / 92$ \\
\hline FB532* * & Male & $20-40$ & $a$ & $7 / 18 / 92$ \\
\hline FB534 & Male & $4-6$ & 9 & $7 / 19 / 92$ \\
\hline FB536 & Male & $4-6$ & $\mathrm{~h}$ & $7 / 19 / 92$ \\
\hline FB538 & Male & $5-7$ & $\mathrm{~h}$ & $7 / 19 / 92$ \\
\hline RT412 & Male & 2 & g & $7 / 10 / 92$ \\
\hline
\end{tabular}


Table 1, key:

* Refer to figure 1 for map of capture locations * * Members of a group of animals caught in the Northeastern portion of the study area. These animals were not resighted again after the capturing and tagging procedure. 


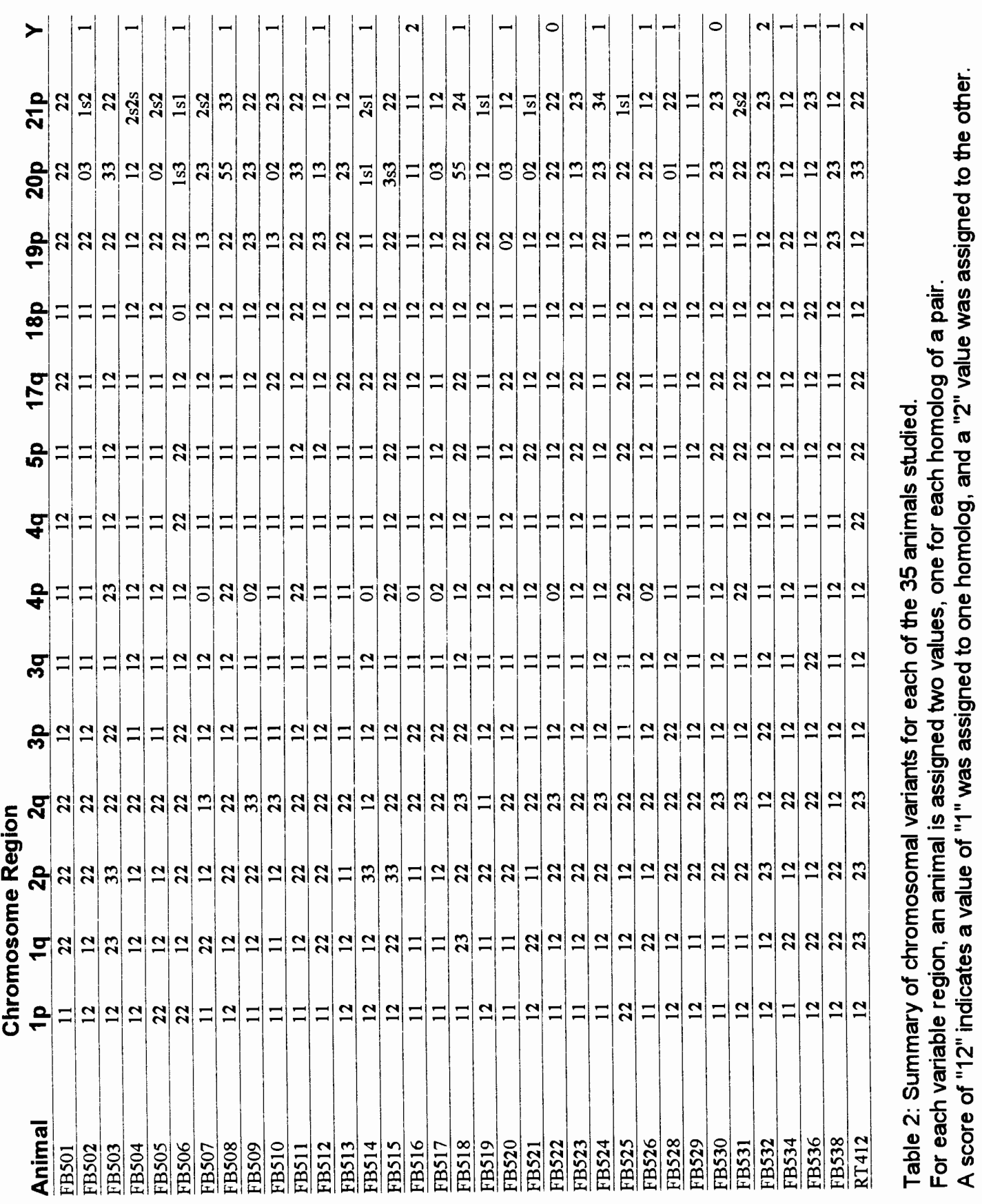




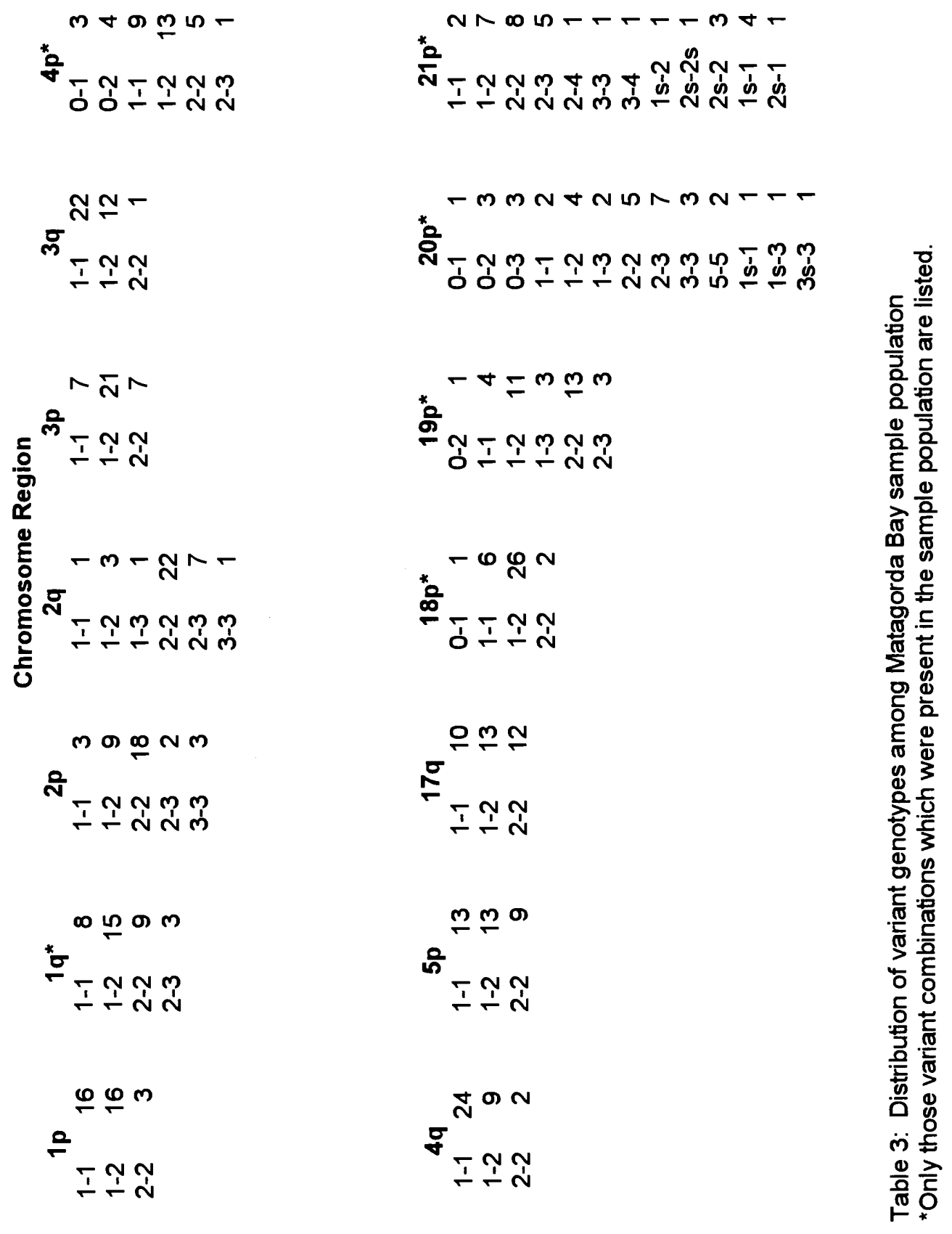




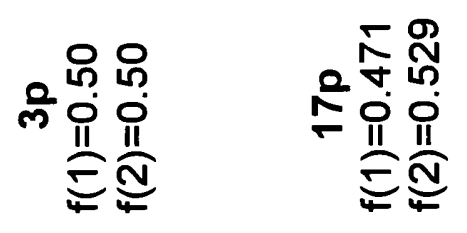
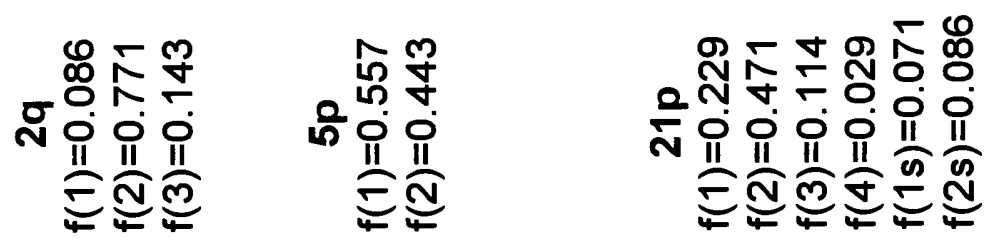

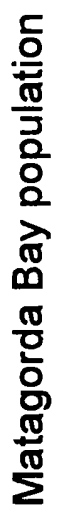
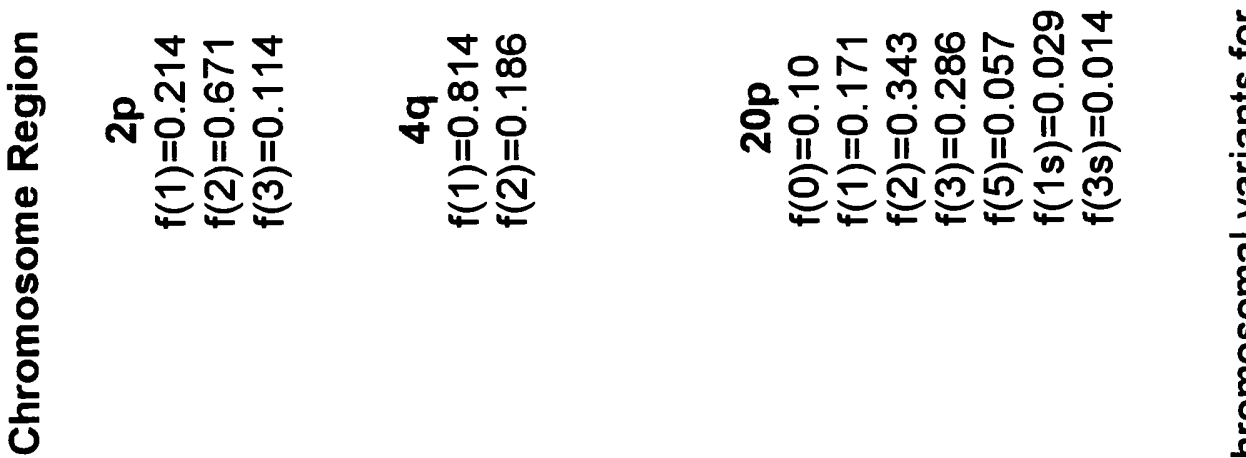

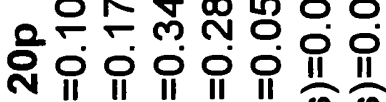

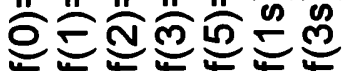

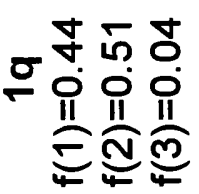
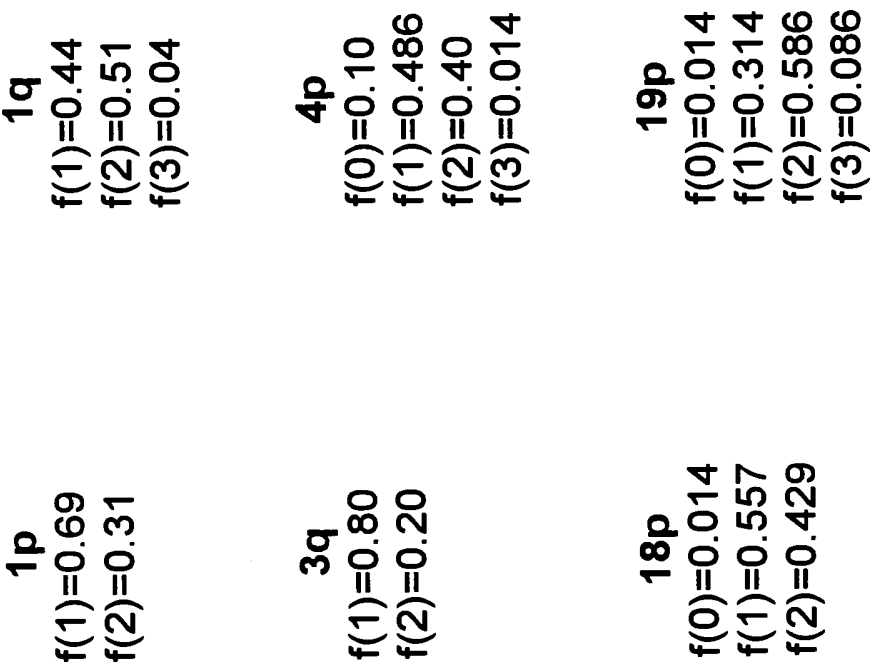

号 


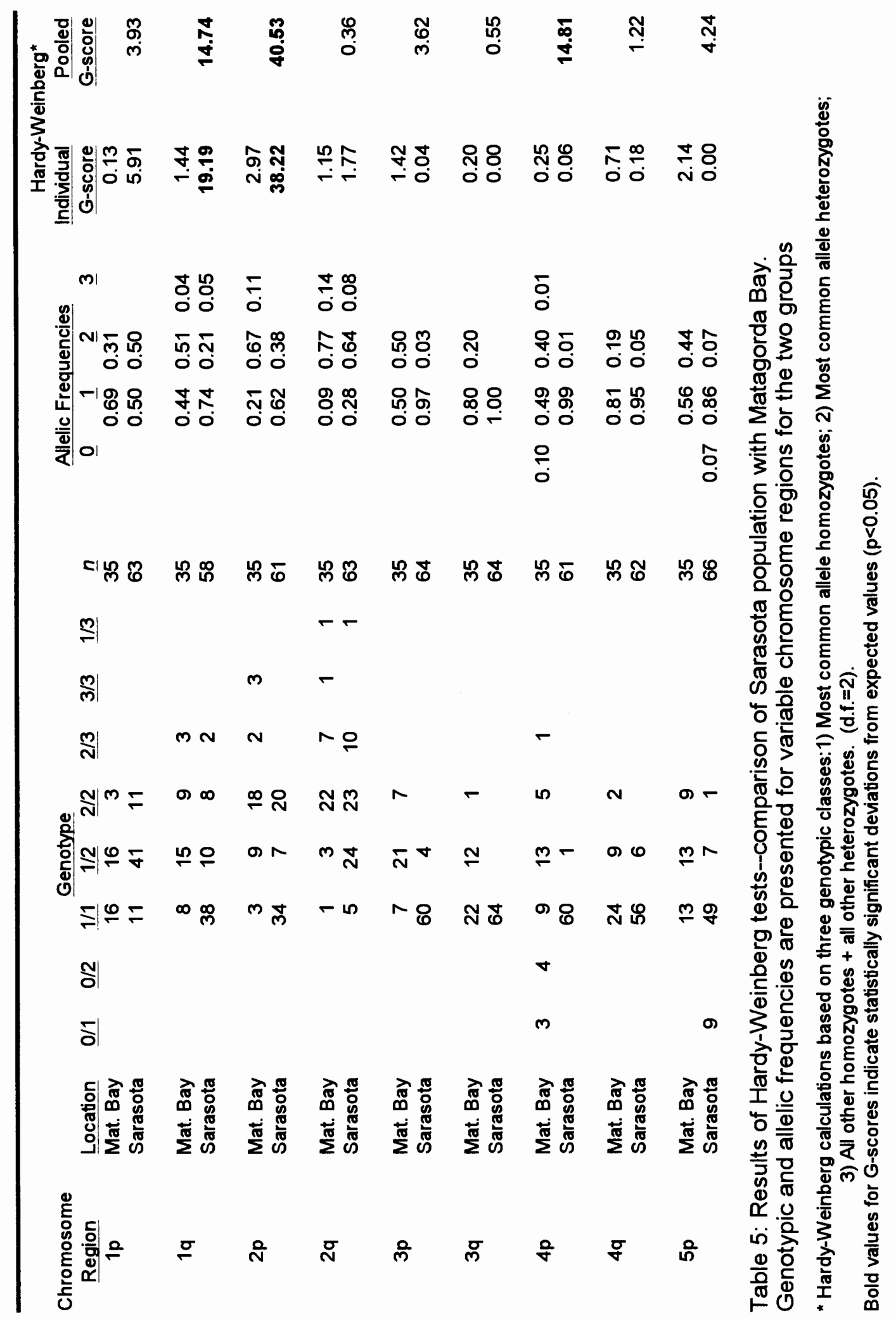




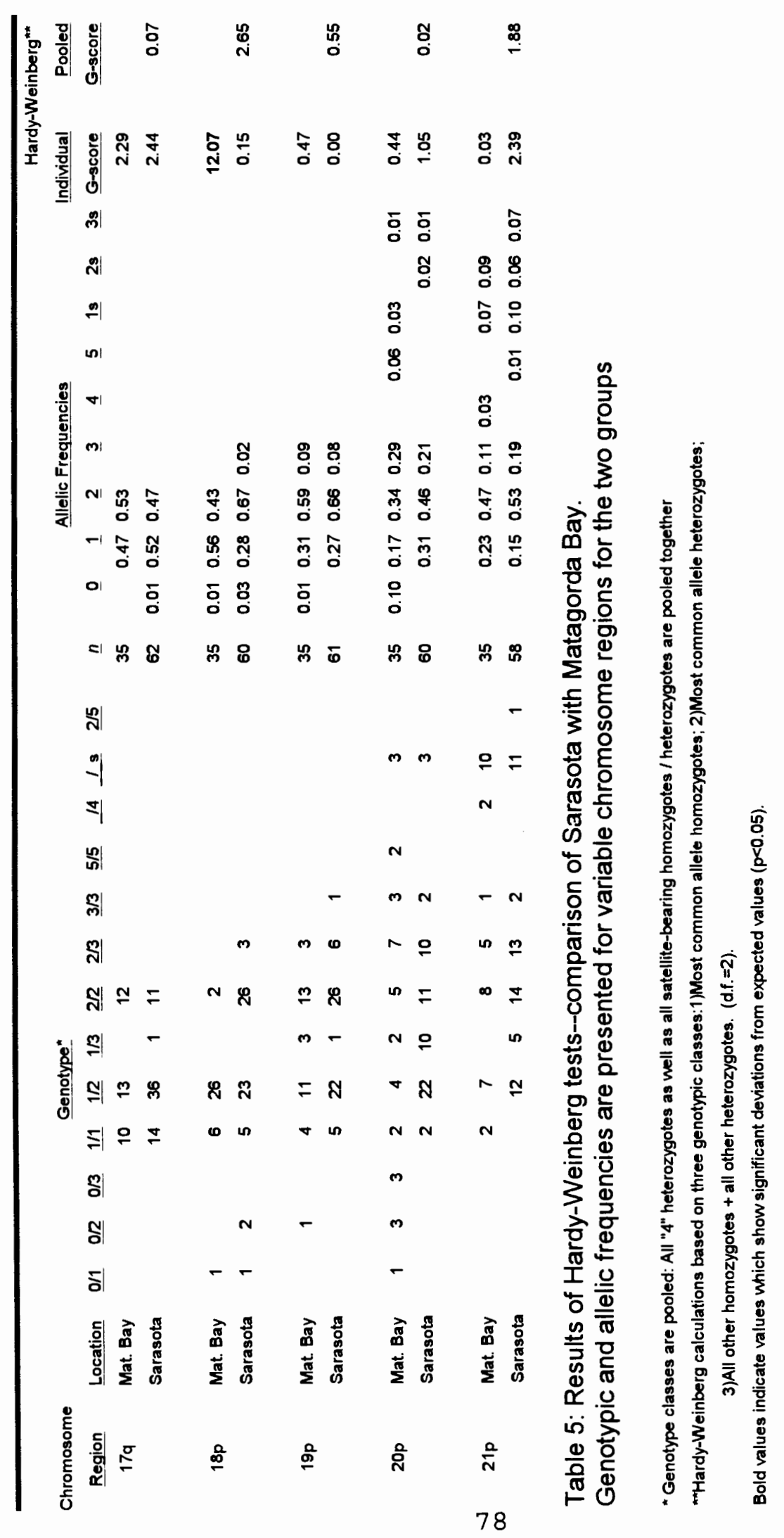




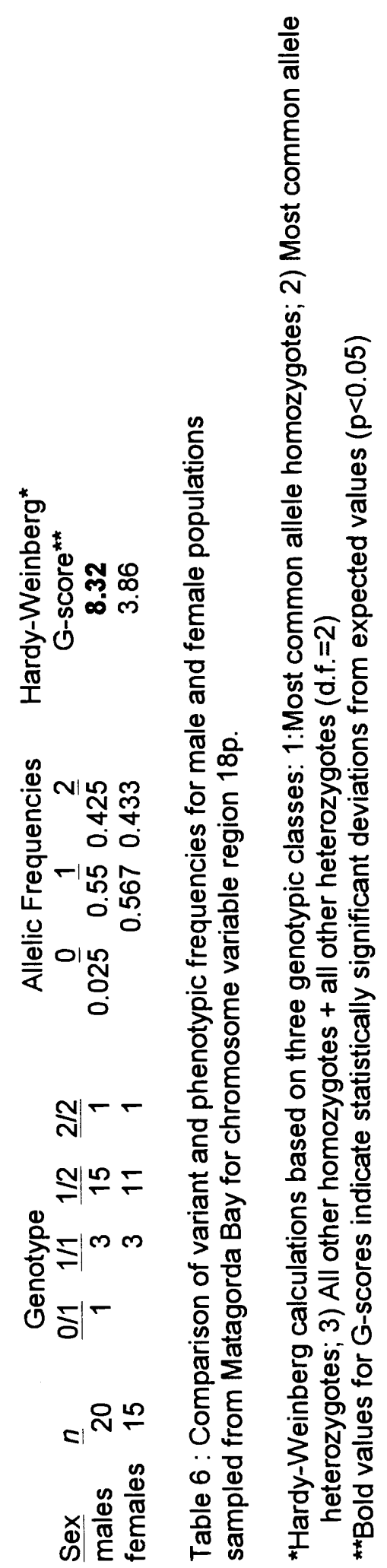




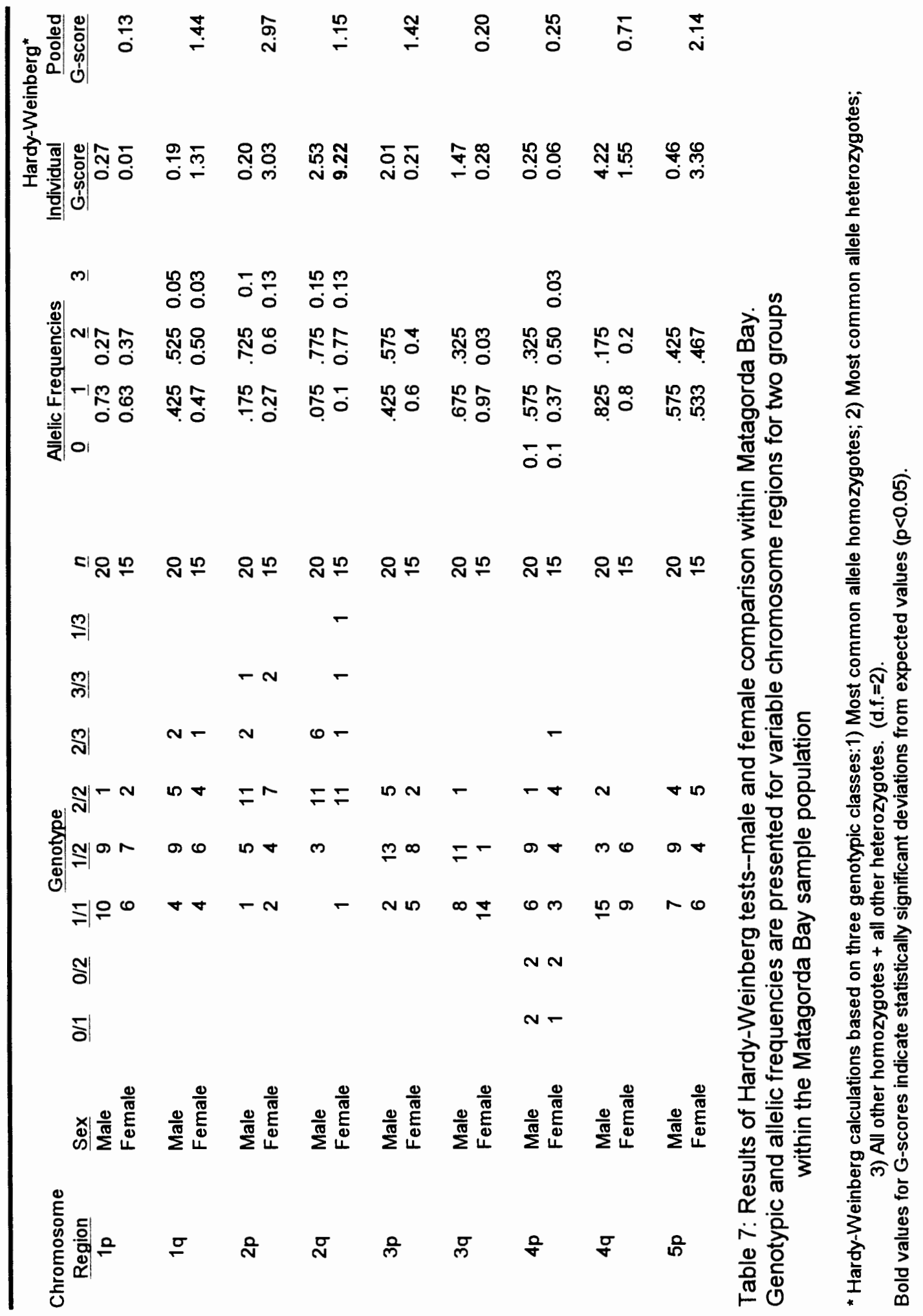




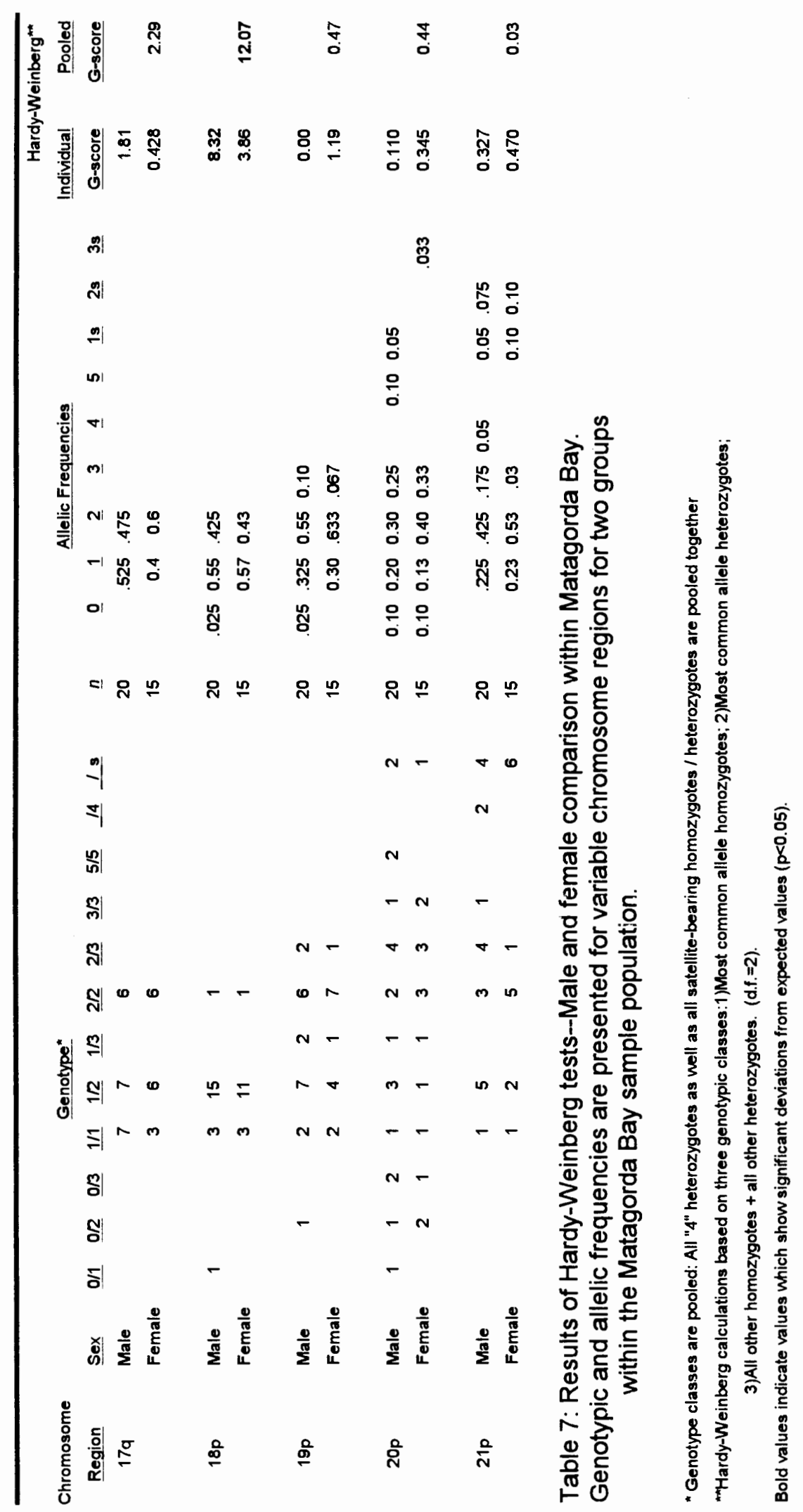




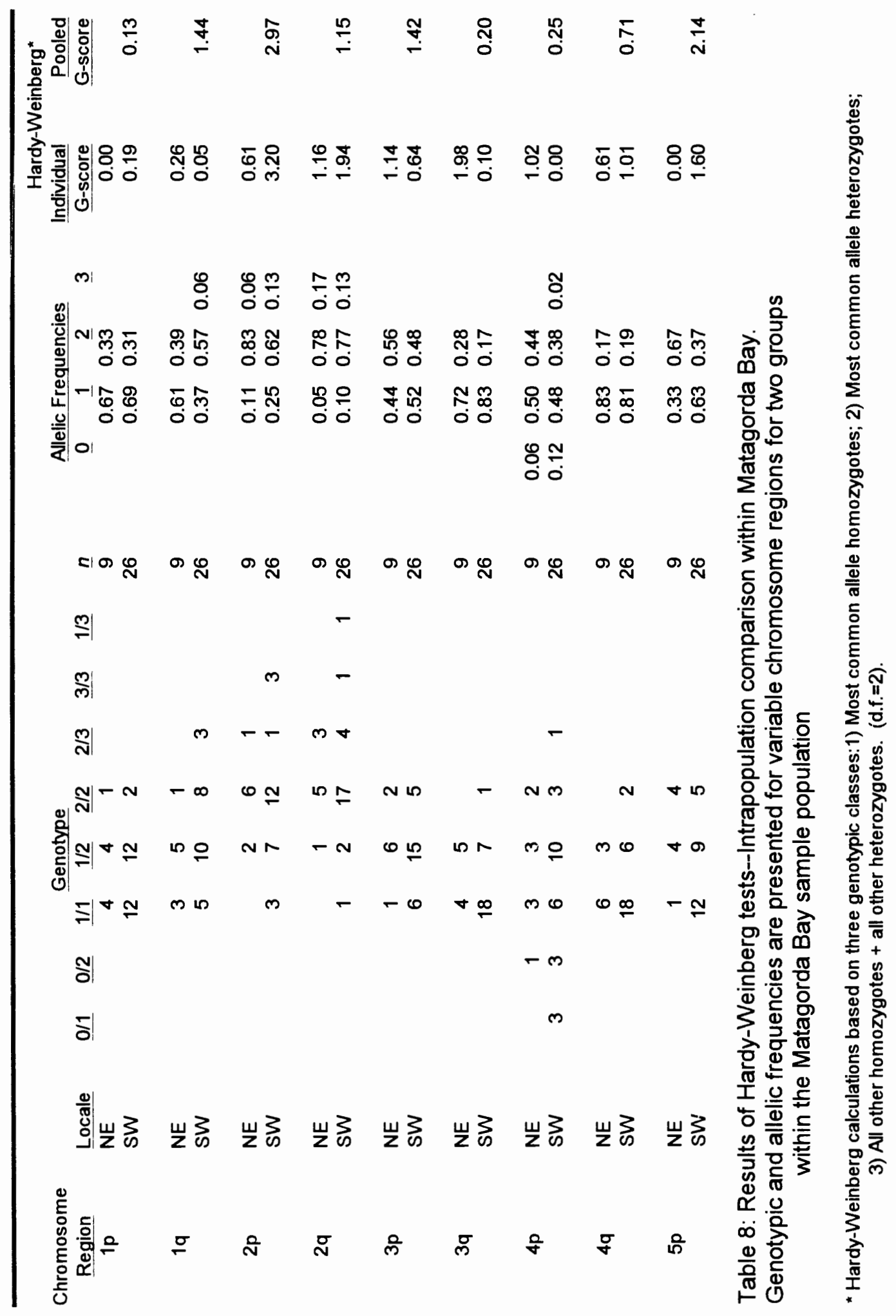




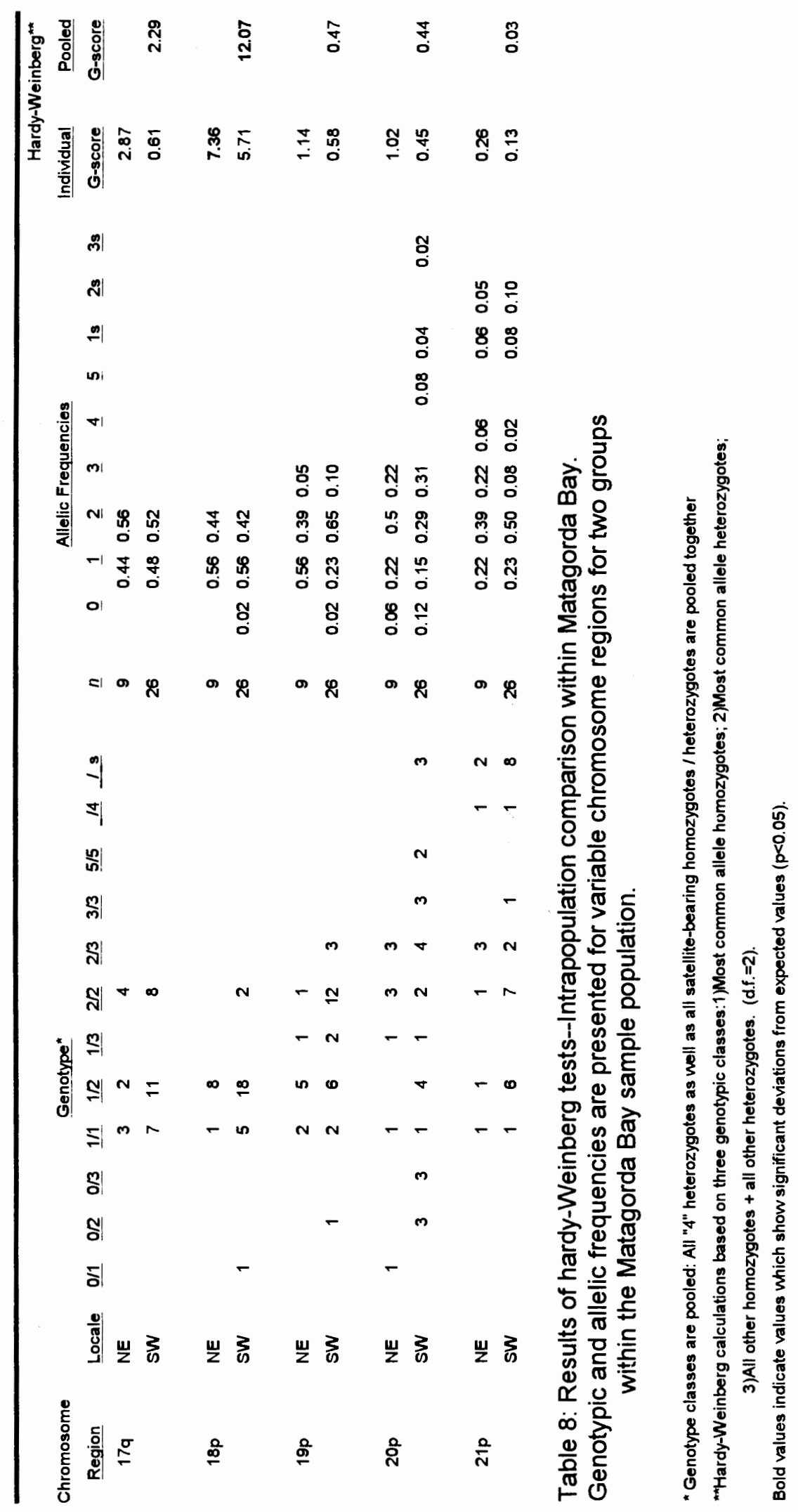




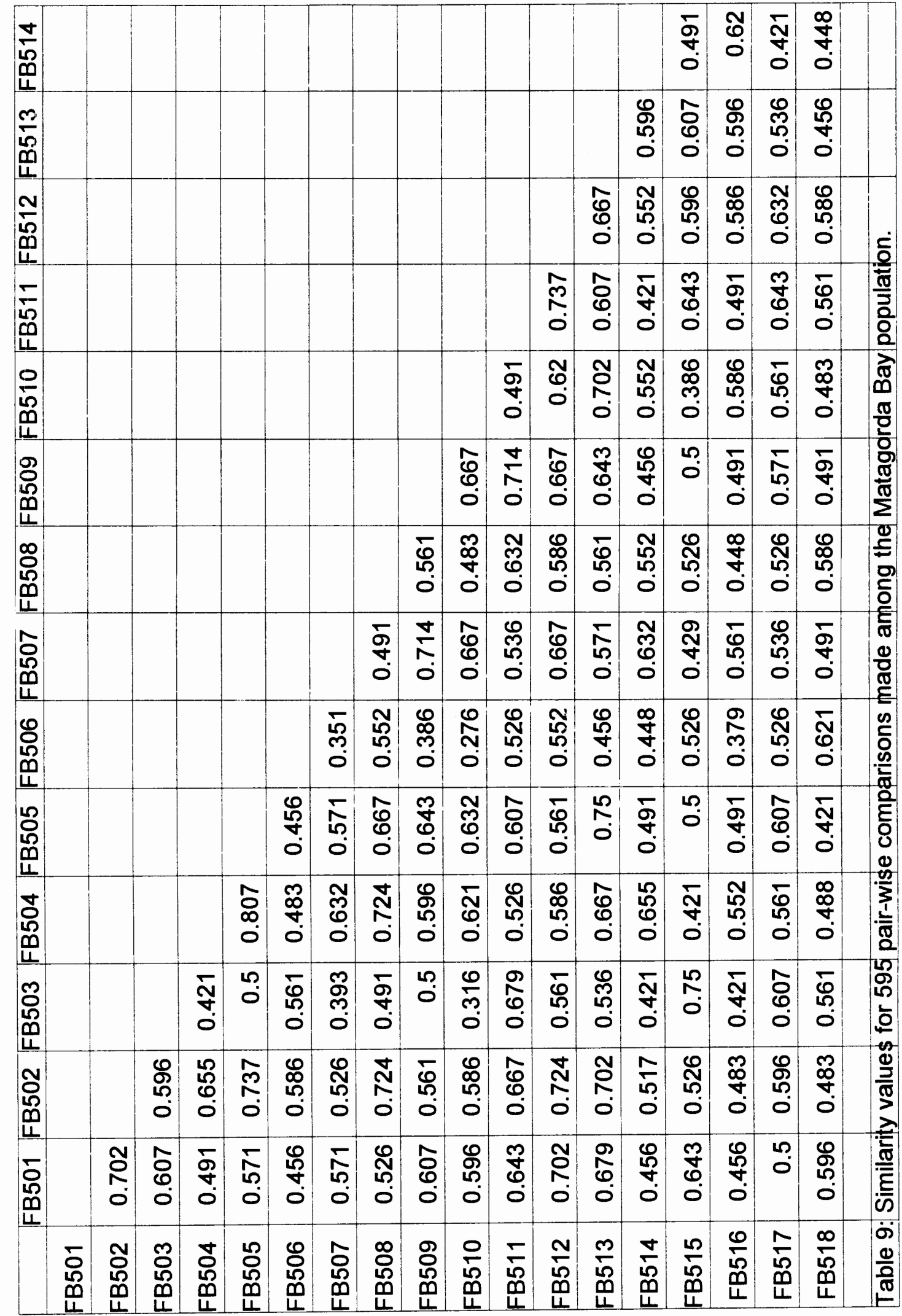




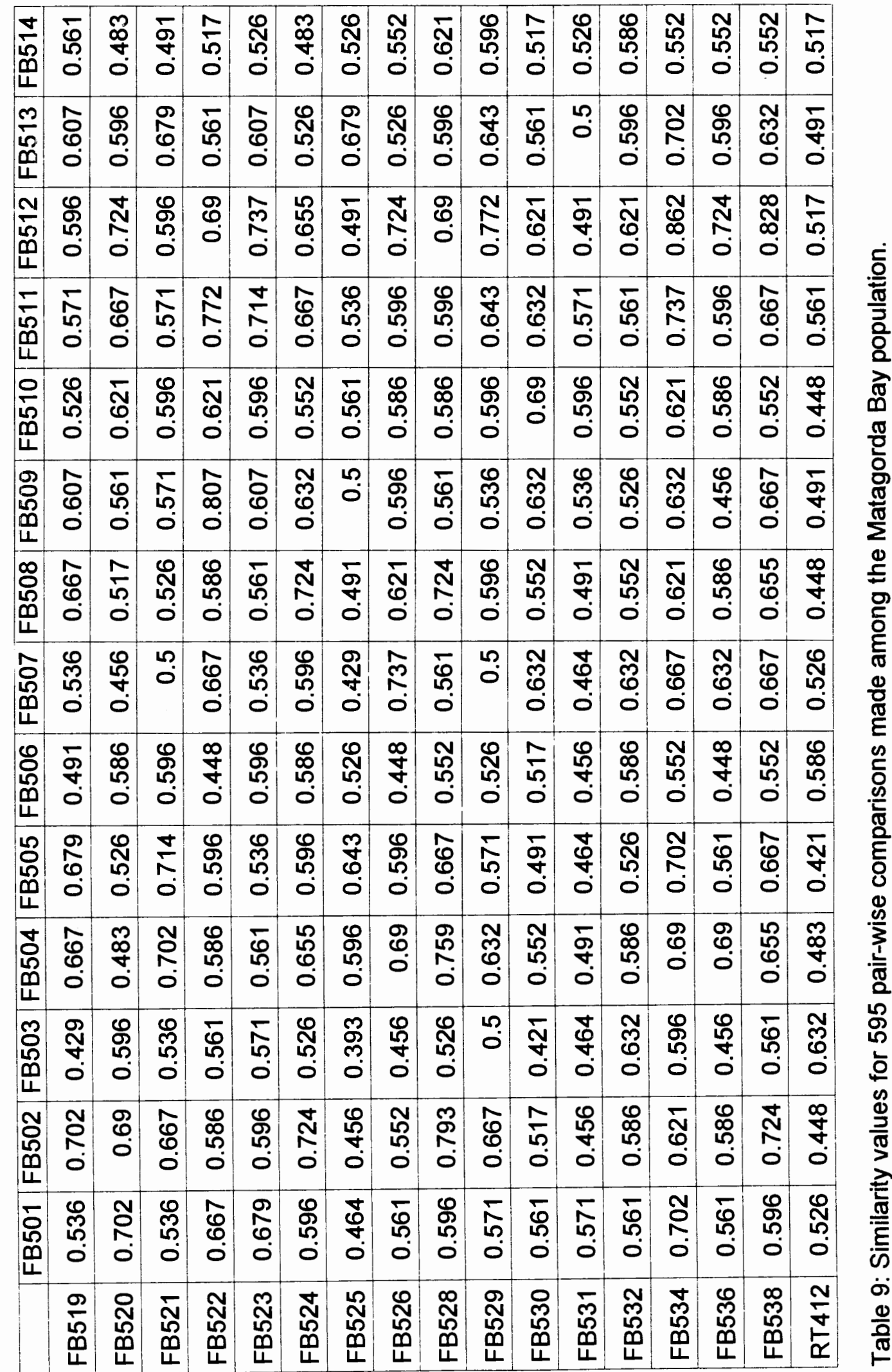




\begin{tabular}{|c|c|c|c|c|c|c|c|c|c|c|c|c|c|c|c|c|c|c|}
\hline 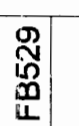 & & & & & & & & & & & & & & $\mid \begin{array}{l}0 \\
\vdots \\
0\end{array}$ & 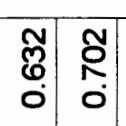 & $\begin{array}{l}\widehat{\sharp} \\
\stackrel{0}{0}\end{array}$ & & \\
\hline 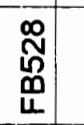 & & & & & & & & & & & & & 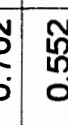 & 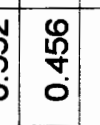 & 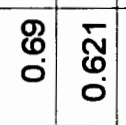 & $\stackrel{\circ}{\circ}$ & & \\
\hline 总 & & & & & & & & & & & & $\begin{array}{ll}5 \\
\end{array}$ & & 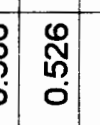 & 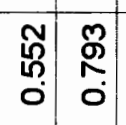 & & & \\
\hline 㐘 & & & & & & & & & & & $\begin{array}{l} \\
\\
0\end{array}$ & 5 & 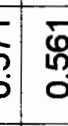 & $\mid \begin{array}{l}\frac{1}{5} \\
0\end{array}$ & 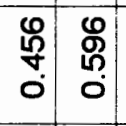 & $\begin{array}{l}\text { g. } \\
\\
\end{array}$ & & \\
\hline 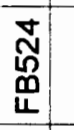 & & & & & & & & & & 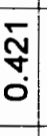 & & & & & & 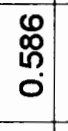 & & \\
\hline 惫 & & & & & & & & & & & & & & 売 & 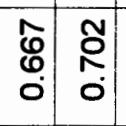 & $\begin{array}{l}0 \\
0 \\
0 \\
0\end{array}$ & & \\
\hline | & & & & & & & & & & 8 & ב⿱ & & & \begin{tabular}{|l|l}
0 \\
$\vdots$ \\
$\vdots$
\end{tabular} & $\begin{array}{lll}\overline{\mathfrak{d}} & \mathbb{N} \\
0 & 0 \\
\end{array}$ & 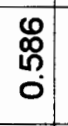 & 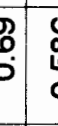 & \\
\hline 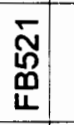 & & & & & & & & 0 & $\begin{array}{l} \\
\\
0 \\
0 \\
0\end{array}$ & \begin{tabular}{|c|}
$\mathscr{0}$ \\
0 \\
0 \\
0 \\
\end{tabular} & & & & 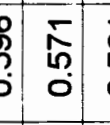 & & $\begin{array}{l}0 \\
0 \\
0 \\
0\end{array}$ & : & \\
\hline 敢 & & & & & & $\begin{array}{l}0 \\
0 \\
0 \\
0\end{array}$ & $\begin{array}{l}\tilde{0} \\
0 \\
0 \\
0 \\
0\end{array}$ & 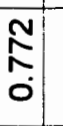 & in & $\bar{g}$ & 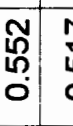 & & & & & 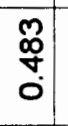 & & \\
\hline 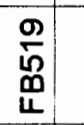 & & & & & 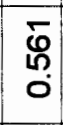 & $\begin{array}{l}\hat{0} \\
\mathrm{o} \\
0\end{array}$ & $\begin{array}{l}0 \\
0 \\
0 \\
0\end{array}$ & $\begin{array}{l}\text { 勨 } \\
0\end{array}$ & $\tilde{\tilde{\mathscr{E}}}$ & & 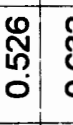 & & & 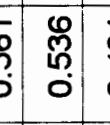 & 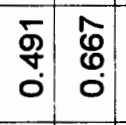 & $\begin{array}{l}\bar{g} \\
\\
\end{array}$ & \begin{tabular}{c}
$c$ \\
\hdashline \\
0
\end{tabular} & \\
\hline 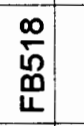 & & & & $\begin{array}{l}\overline{\bar{y}} \\
0\end{array}$ & 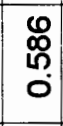 & $\begin{array}{l}0 \\
0 \\
0 \\
0 \\
0\end{array}$ & $\begin{array}{l}0 \\
0 \\
0 \\
0 \\
0\end{array}$ & 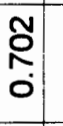 & $\begin{array}{l}0 \\
0 \\
0 \\
0 \\
0\end{array}$ & 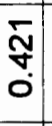 & $\bar{\vdots}$ & & & 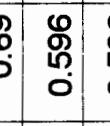 & & $\begin{array}{l}0 \\
0 \\
0 \\
0 \\
0\end{array}$ & & \\
\hline $\begin{array}{l}\hat{n} \\
\bar{i} \\
0 \\
u\end{array}$ & & & 8 & 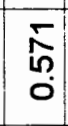 & 今̂. & $\begin{array}{l}0 \\
\stackrel{0}{0} \\
\circ\end{array}$ & $\begin{array}{l}\widehat{0} \\
: \\
0\end{array}$ & 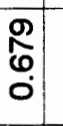 & 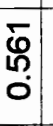 & & 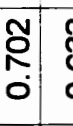 & & & 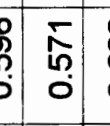 & 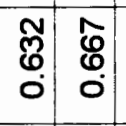 & 商 & $\begin{array}{l}8 \\
\\
\end{array}$ & \\
\hline 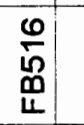 & & 0 & \begin{tabular}{|l|}
\multirow{2}{*}{} \\
0 \\
0
\end{tabular} & & $\begin{array}{l}1 \\
5 \\
0\end{array}$ & $\begin{array}{l}0 \\
0 \\
0 \\
0 \\
0\end{array}$ & 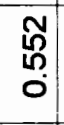 & 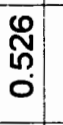 & $\frac{8}{7}$ & 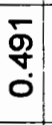 & 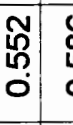 & $\begin{array}{l}\dot{b} \\
\dot{b}\end{array}$ & 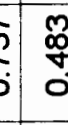 & 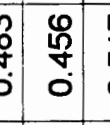 & 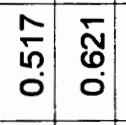 & 年 & & \\
\hline 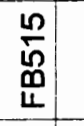 & 离 & & & & $\begin{array}{l}0 \\
0 \\
0 \\
0\end{array}$ & $\begin{array}{l}0 \\
0 \\
0 \\
0 \\
\end{array}$ & $\begin{array}{l}\overline{0} \\
0 \\
0 \\
\end{array}$ & . & 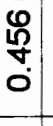 & & & 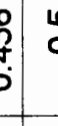 & 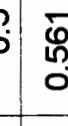 & $0 \begin{array}{c}9 \\
0 \\
0 \\
0\end{array}$ & & 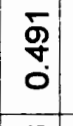 & & \\
\hline & 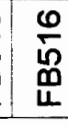 & $\begin{array}{l}\hat{\bar{g}} \\
\text { 总 }\end{array}$ & 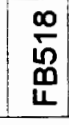 & 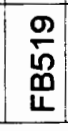 & 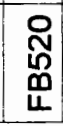 & - & 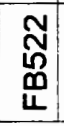 & & & & 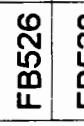 & 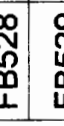 & 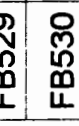 & 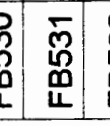 & 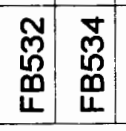 & 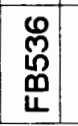 & . & \\
\hline
\end{tabular}




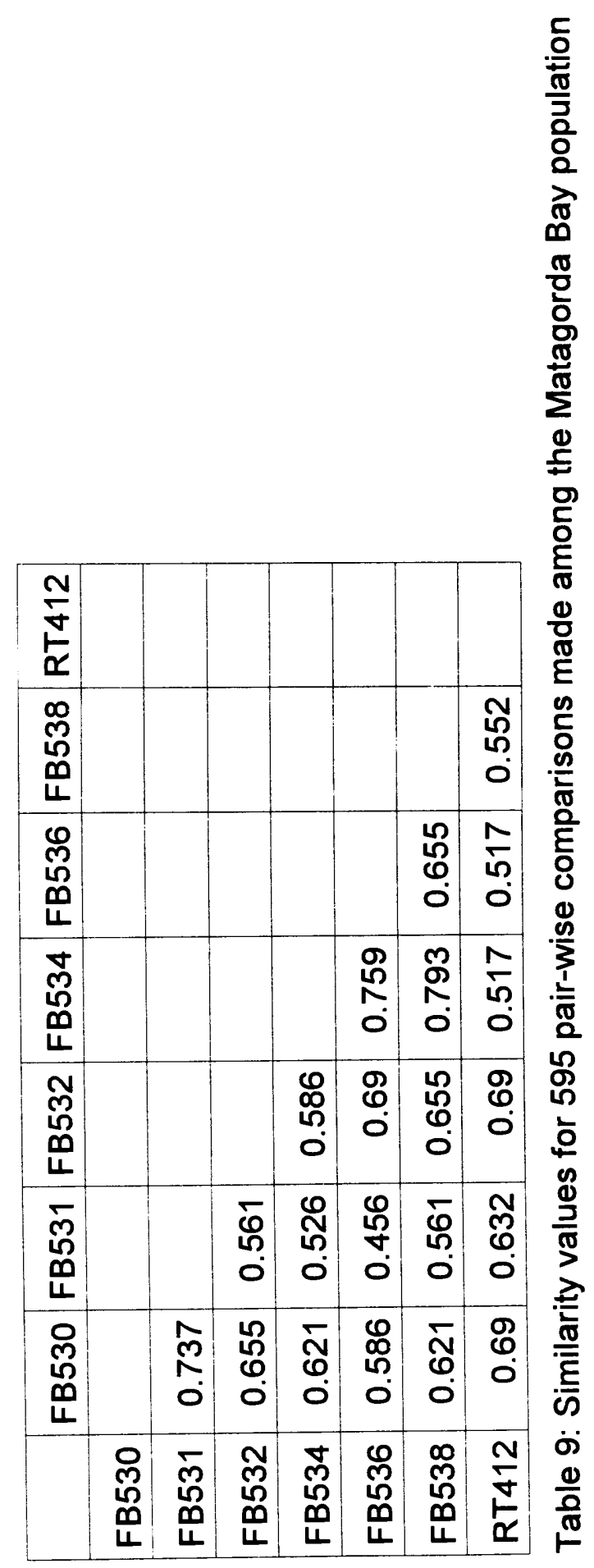




\begin{tabular}{|c|c|c|c|}
\hline $\begin{array}{c}\text { Chromosome } \\
\text { Region }\end{array}$ & $\begin{array}{c}\text { Similarity } \\
\text { Index: } \\
\text { Sarasota vs. } \\
\text { Matagorda } \\
\text { Bay }\end{array}$ & $\begin{array}{c}\text { Similarity } \\
\text { Index: } \\
\text { Matagorda } \\
\text { Bay Males vs } \\
\text { Females }\end{array}$ & $\begin{array}{c}\text { Similarity } \\
\text { Index: } \\
\text { NE vs. SW }\end{array}$ \\
\hline $1 p$ & 0.94 & 0.98 & 1.00 \\
\hline $1 q$ & 0.84 & 1.00 & 0.91 \\
\hline $2 p$ & 0.75 & 0.98 & 0.96 \\
\hline $2 q$ & 0.96 & 1.00 & 1.00 \\
\hline $3 p$ & 0.73 & 0.94 & 0.99 \\
\hline $3 q$ & 0.97 & 0.91 & 0.99 \\
\hline $4 p$ & 0.77 & 0.91 & 0.99 \\
\hline $4 q$ & 0.98 & 1.00 & 1.00 \\
\hline $5 p$ & 0.83 & 1.00 & 0.84 \\
\hline $17 q$ & 0.99 & 0.97 & 1.00 \\
\hline $18 p$ & 0.87 & 1.00 & 1.00 \\
\hline $19 p$ & 1.00 & 0.99 & 0.81 \\
\hline $20 p$ & 0.92 & 0.94 & 0.90 \\
\hline $21 p$ & 0.97 & 0.95 & 0.94 \\
\hline Total & 0.88 & 0.97 & 0.95 \\
\hline Index & & & \\
\hline
\end{tabular}

Table 10: Comparisons of similarity index values for three different pairs of population subgroups. 


\begin{tabular}{|l|l|l|l|}
\hline $\begin{array}{l}\text { Suspected } \\
\text { Mother }\end{array}$ & $\begin{array}{l}\text { Suspected } \\
\text { Calf }\end{array}$ & $\begin{array}{l}\text { Similarity } \\
\text { Value }\end{array}$ & z-score \\
\hline FB503 & FB508 & 0.491 & -1.01 \\
\hline FB507 & FB509 & 0.714 & 1.47 \\
\hline FB511 & FB513 & 0.607 & 0.277 \\
\hline FB515 & FB517 & 0.536 & -0.511 \\
\hline FB520 & FB521 & 0.596 & 0.155 \\
\hline
\end{tabular}

Table 11: Similarity values and Z-scores for the five potential mother and calf pairs from the Matagorda Bay sample. 


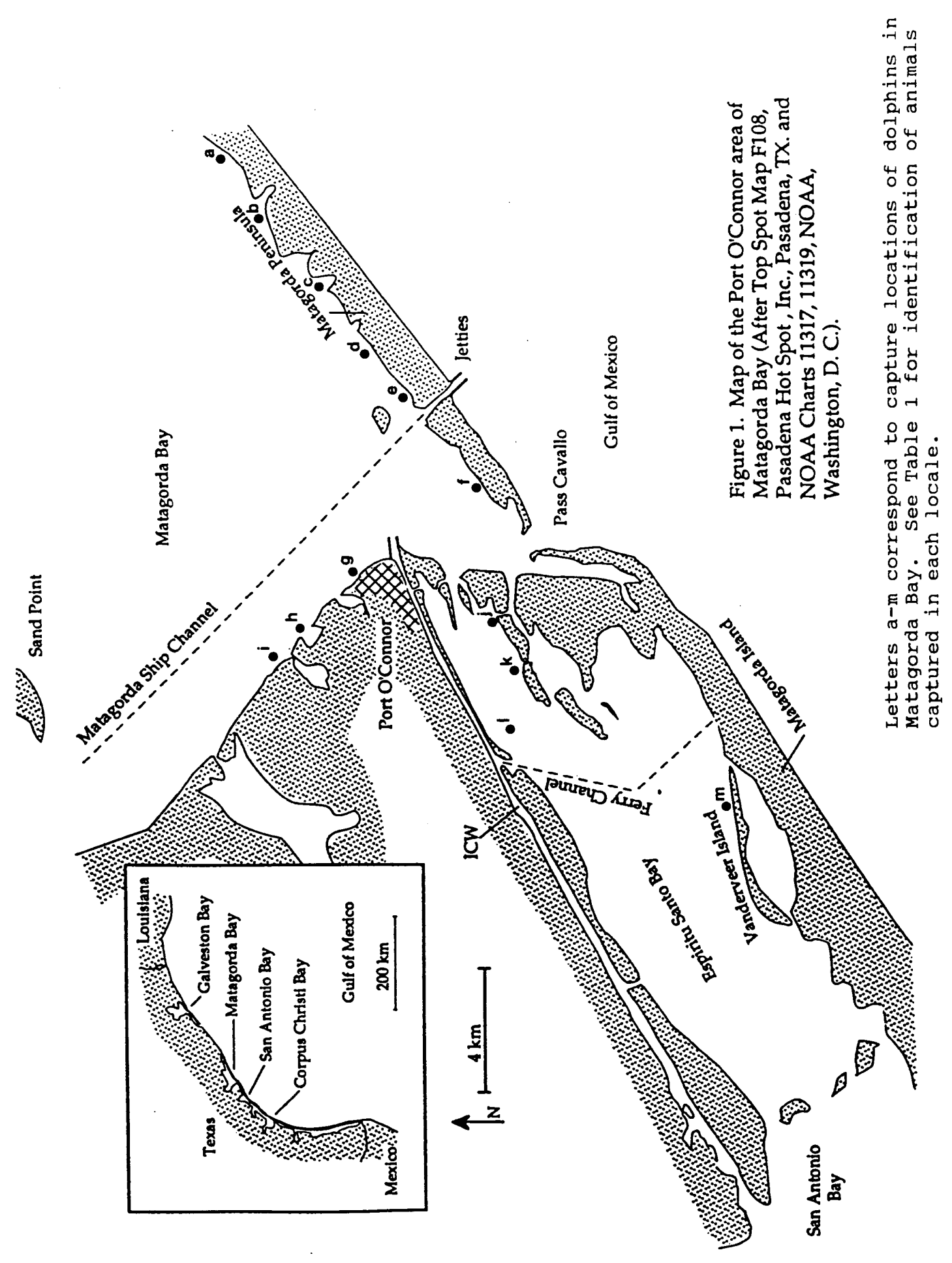




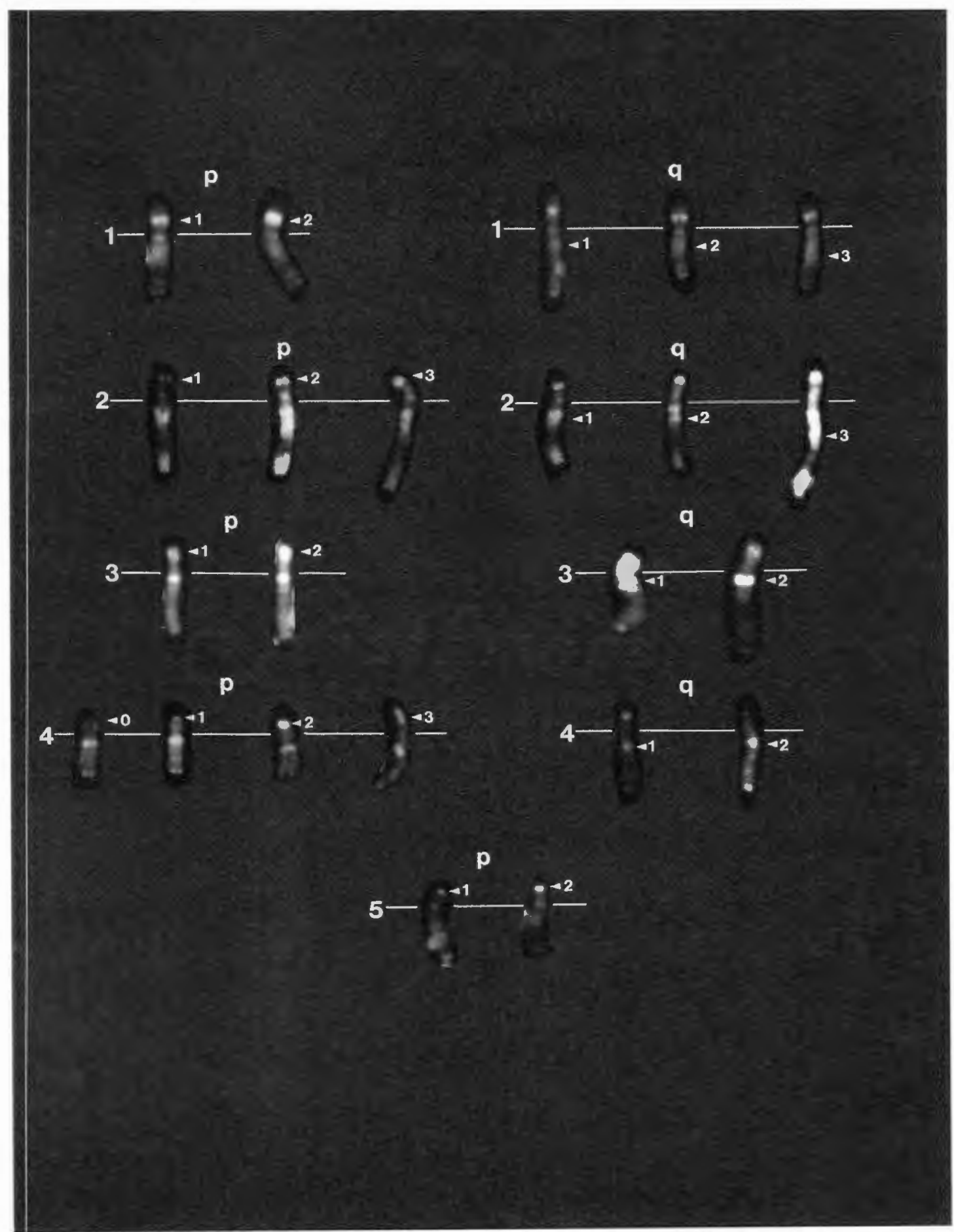

Figure 2: Chromosome variants identified among the Matagorda Bay animals. 


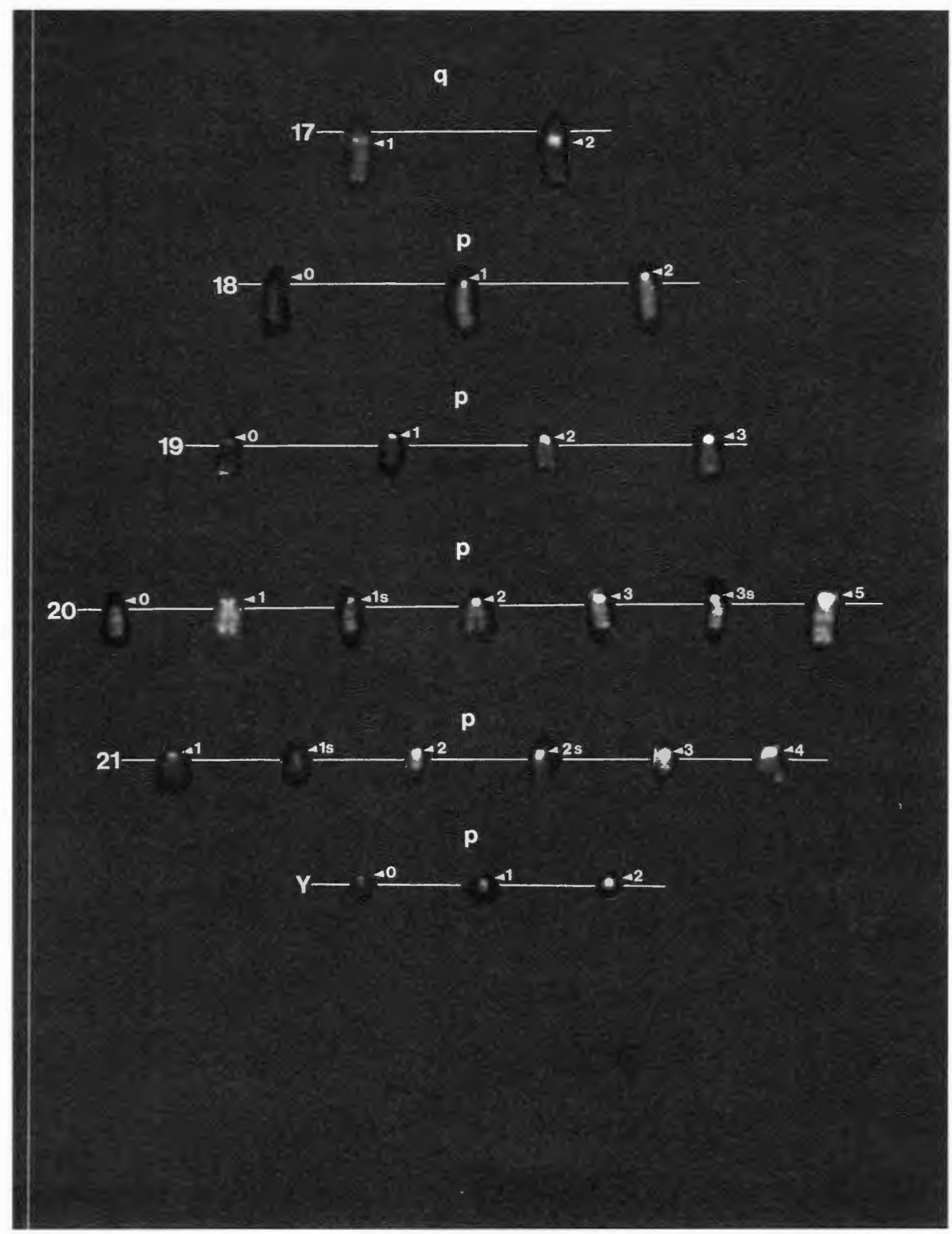




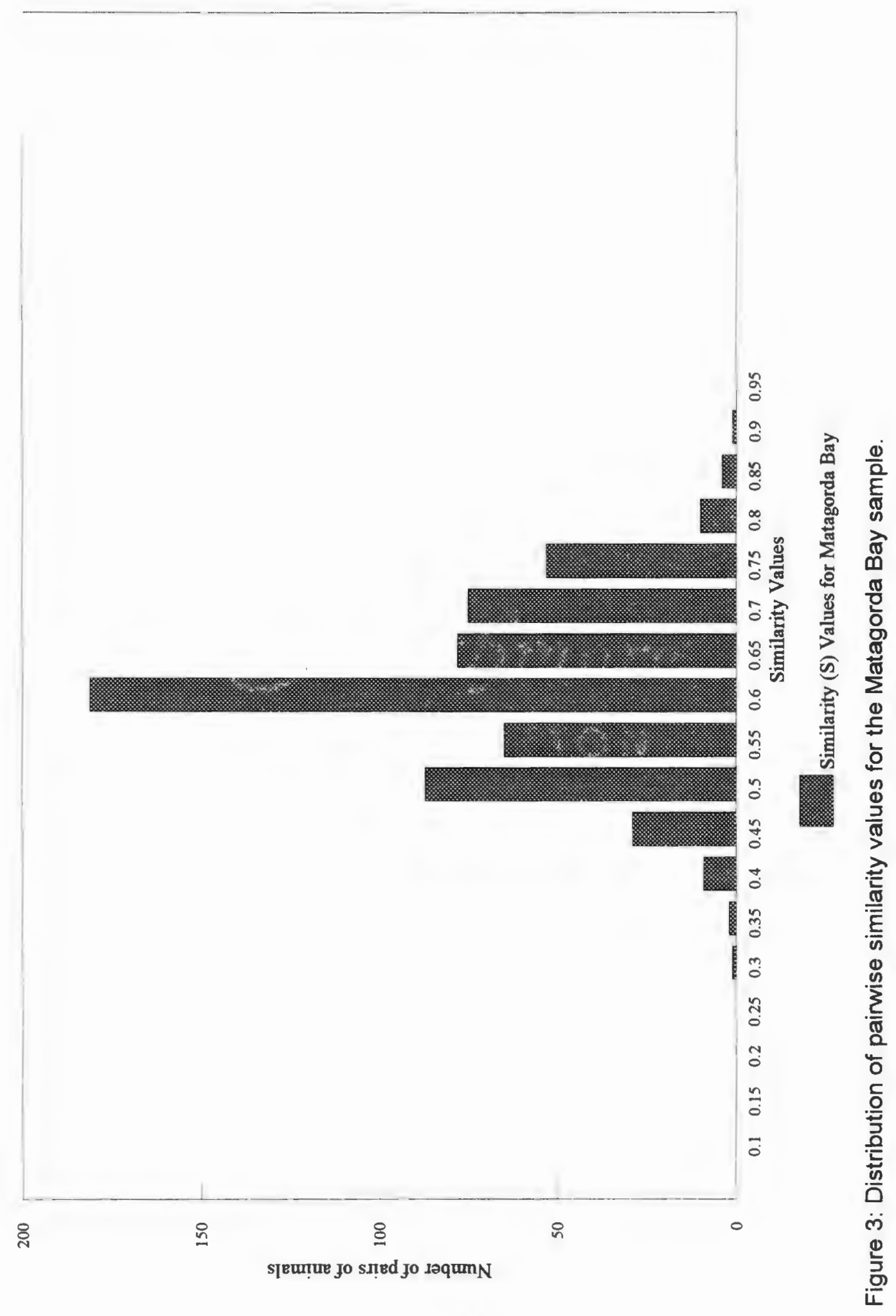




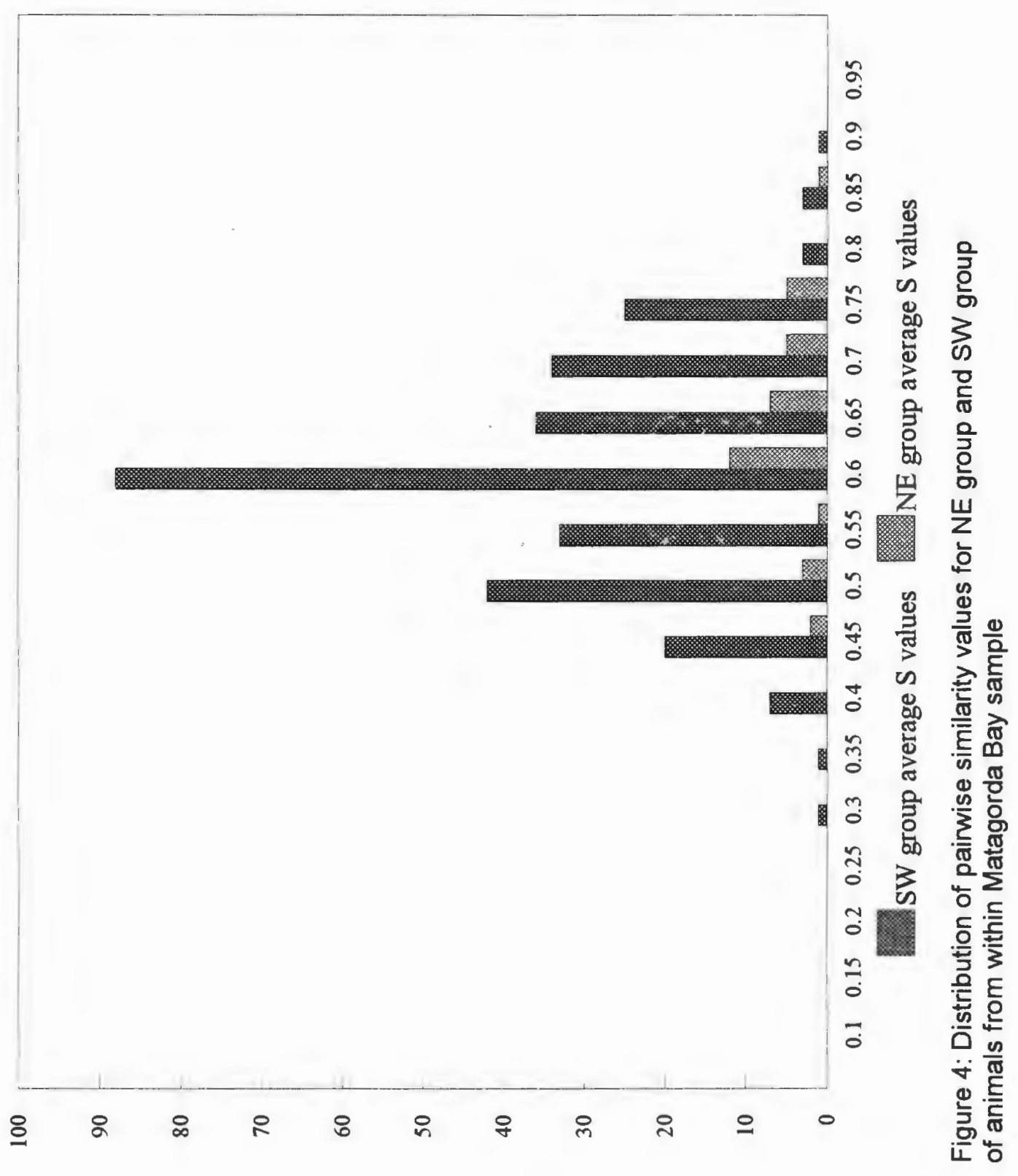


Estimated age, in years, of each animal

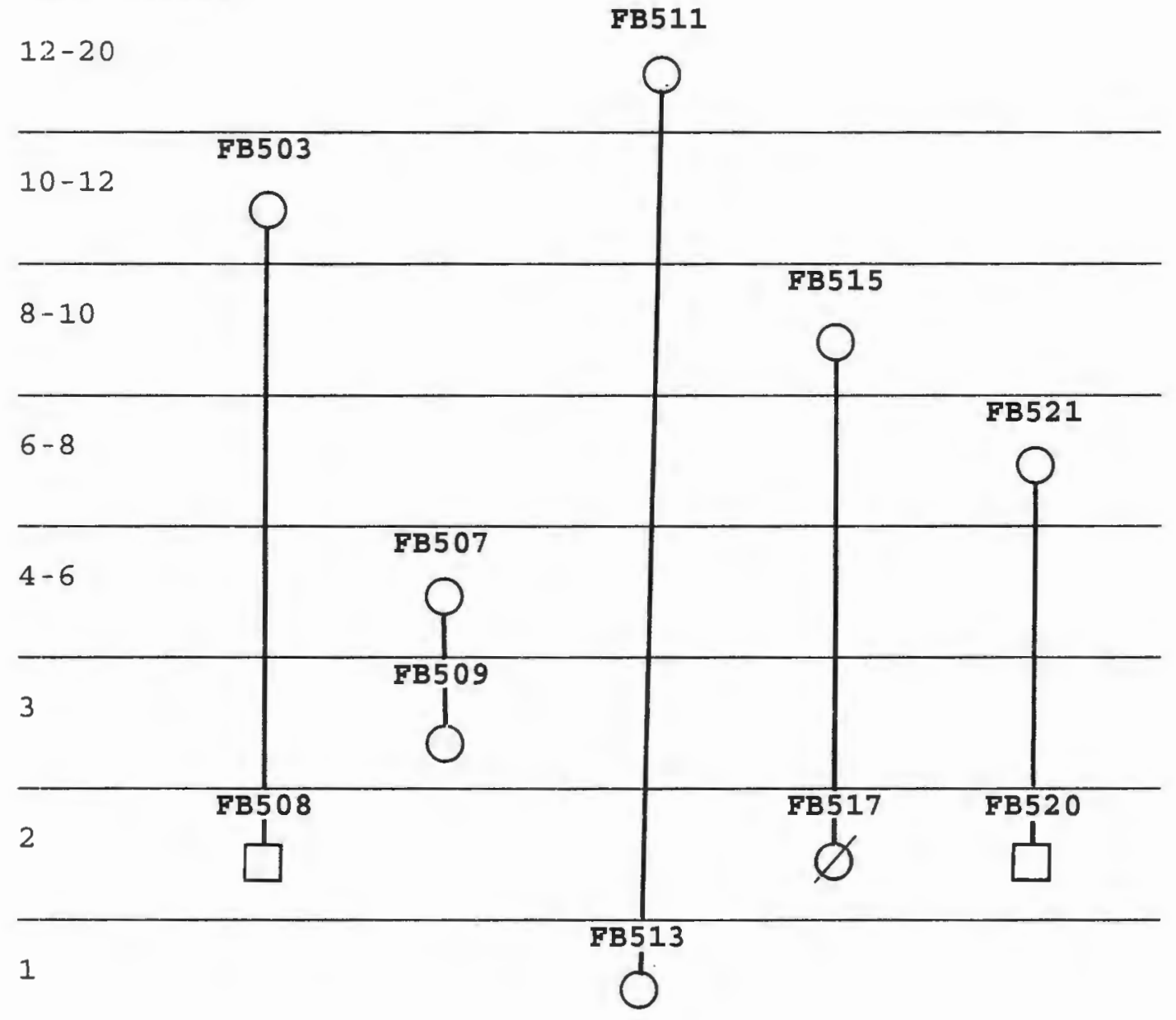
OFemale
$\square$ Male
$\varnothing_{\text {Dead }}$

Figure 5: Ages and sex of suspected mother-calf pairs 


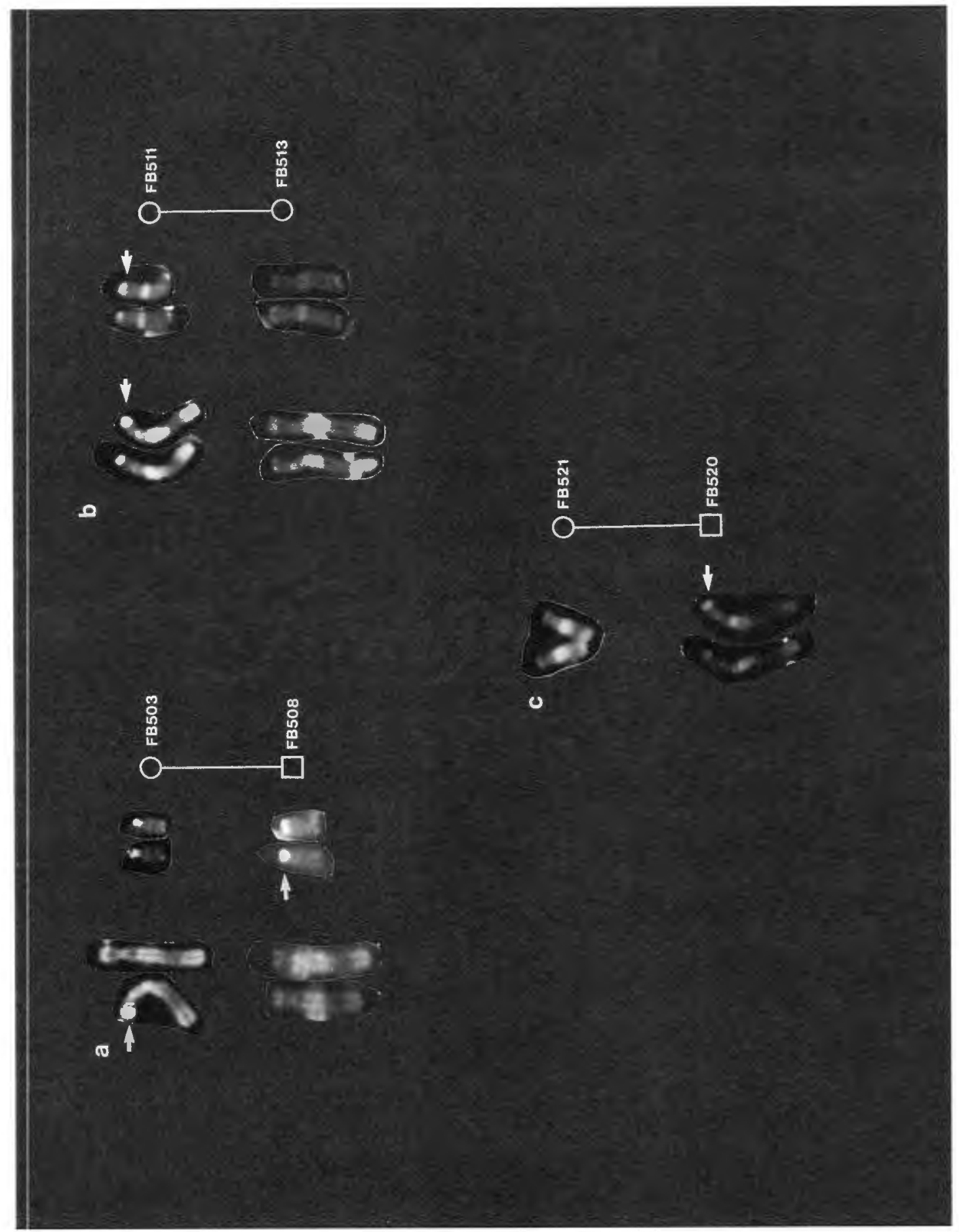

Figure 6: Discrepant chromosome pairs in suspected mother-calf pairs 96 


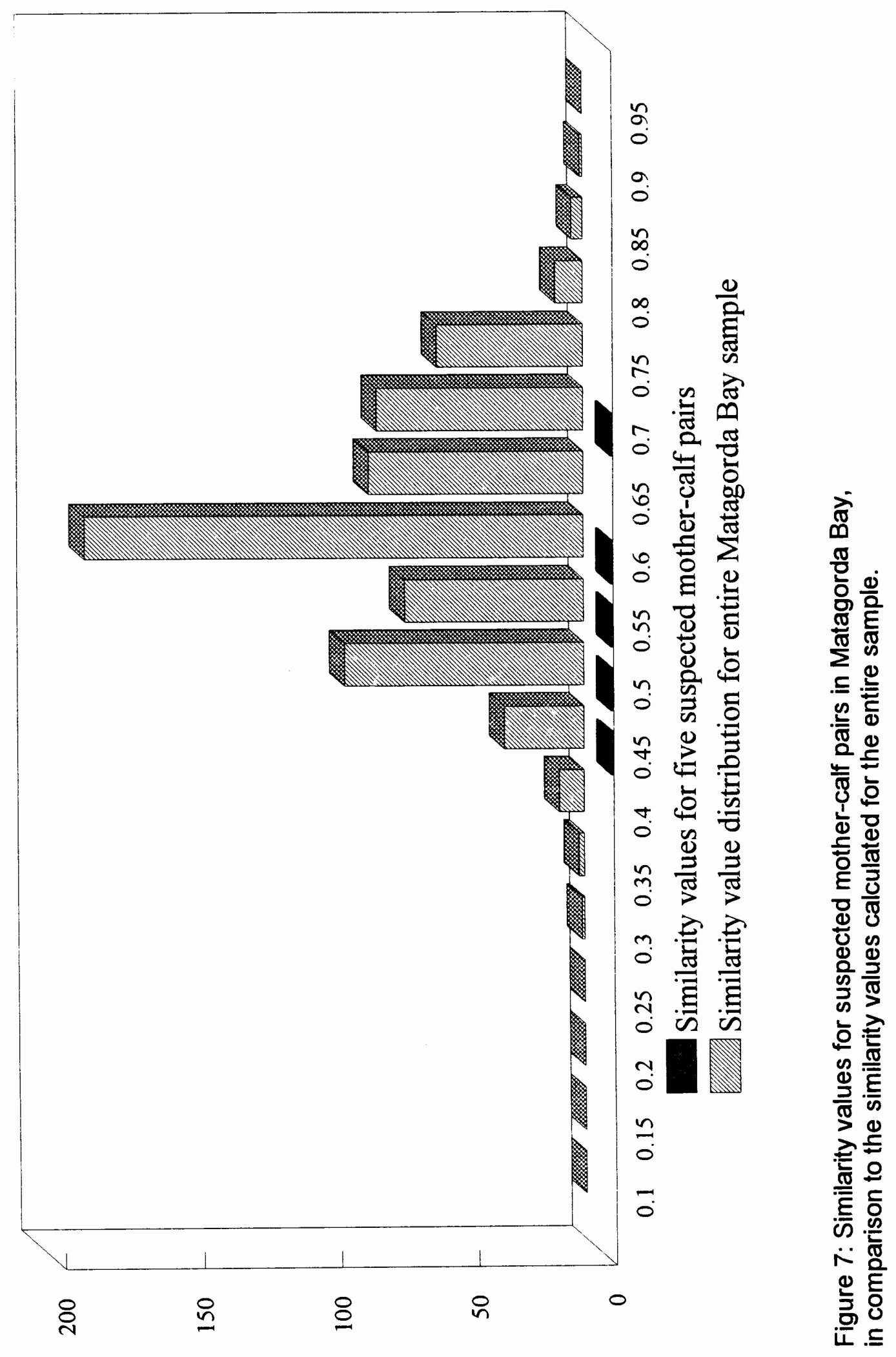



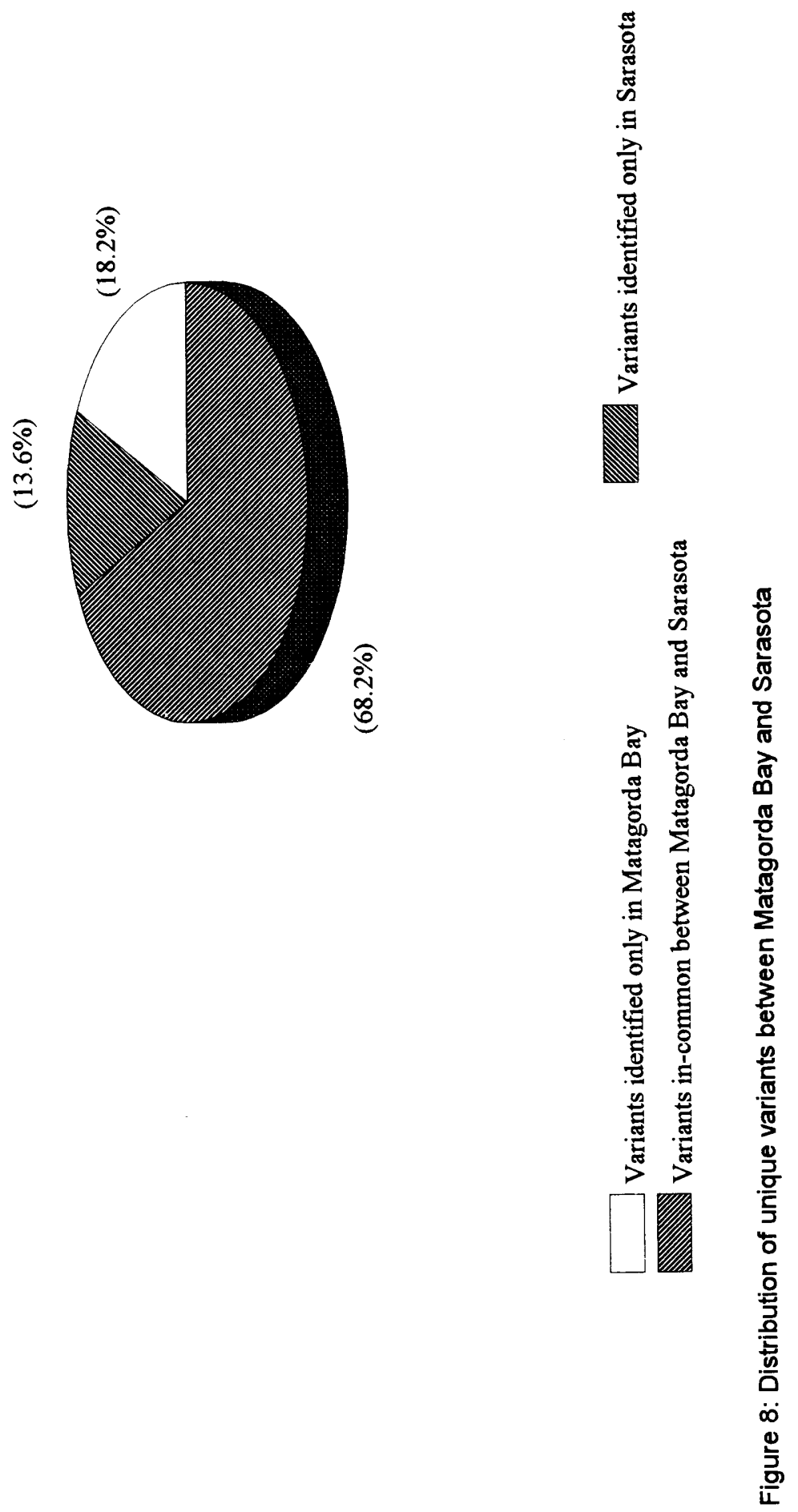